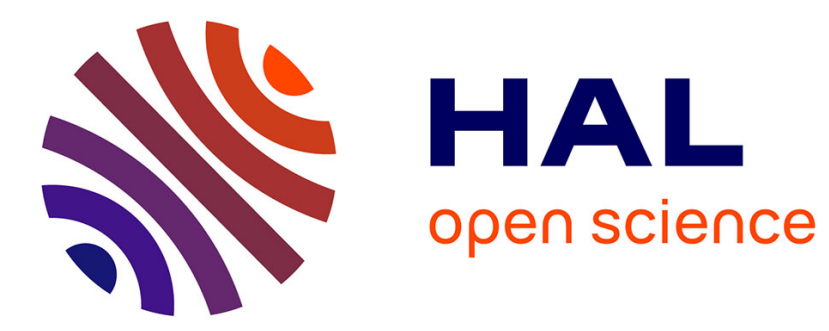

\title{
Hagiographie et historiographie mérovingienne dans la musique liturgique en Gaule septentrionale (VIIIe et IXe siècles)
}

\author{
Jean-François Goudesenne
}

\section{- To cite this version:}

Jean-François Goudesenne. Hagiographie et historiographie mérovingienne dans la musique liturgique en Gaule septentrionale (VIIIe et IXe siècles). Revue du Nord, 2001, 83 (341), pp.485-517. 10.3917/rdn.341.0485 . halshs-03504314

\section{HAL Id: halshs-03504314 \\ https://shs.hal.science/halshs-03504314}

Submitted on 10 Jan 2022

HAL is a multi-disciplinary open access archive for the deposit and dissemination of scientific research documents, whether they are published or not. The documents may come from teaching and research institutions in France or abroad, or from public or private research centers.
L'archive ouverte pluridisciplinaire $\mathbf{H A L}$, est destinée au dépôt et à la diffusion de documents scientifiques de niveau recherche, publiés ou non, émanant des établissements d'enseignement et de recherche français ou étrangers, des laboratoires publics ou privés. 


\title{
HAGIOGRAPHIE ET HISTORIOGRAPHIE MÉROVINGIENNE DANS LA MUSIQUE LITURGIQUE EN GAULE SEPTENTRIONALE $\left(\mathrm{VIII}^{\mathrm{E}} \mathrm{ET} \mathrm{IX}^{\mathrm{E}}\right.$ SIÈCLES)
}

\author{
Jean-François Goudesenne
}

Association Revue du Nord | «Revue du Nord »

2001/3 n³ 341 | pages 485 à 517

ISSN 0035-2624

DOI $10.3917 /$ rdn.341.0485

Article disponible en ligne à l'adresse :

https://www.cairn.info/revue-du-nord-2001-3-page-485.htm

Distribution électronique Cairn.info pour Association Revue du Nord.

(C) Association Revue du Nord. Tous droits réservés pour tous pays.

La reproduction ou représentation de cet article, notamment par photocopie, n'est autorisée que dans les limites des conditions générales d'utilisation du site ou, le cas échéant, des conditions générales de la licence souscrite par votre établissement. Toute autre reproduction ou représentation, en tout ou partie, sous quelque forme et de quelque manière que ce soit, est interdite sauf accord préalable et écrit de l'éditeur, en dehors des cas prévus par la législation en vigueur en France. Il est précisé que son stockage dans une base de données est également interdit. 


\section{JEAN-FRANÇOIS GOUDESENNE*}

\section{Hagiographie et historiographie mérovingienne dans la musique liturgique en Gaule septentrionale (VIII ${ }^{\mathrm{e}}$ et $\mathrm{IX}^{\mathrm{e}}$ siècles)}

Le culte des saints et l'hagiographie ont fait l'objet depuis une vingtaine d'années d'investigations qui ont réévalué leur rôle, essentiel dans l'histoire politique et religieuse du haut Moyen Âge. Les travaux de P. Brown ${ }^{1}$, Ch. et L. Pietri², G. Philippart, F. Dolbeau, M. Heinzelmann ${ }^{3}$ et de tant d'autres ont élaboré un point de vue selon lequel le culte des saints aux périodes mérovingienne et carolingienne n'était pas qu'un simple phénomène lié aux dévotions populaires, mais aussi un enjeu fondamental de pouvoir, tant pour l'évangélisation des fidèles, que pour la cohérence des systèmes politiques alors en construction. Considérés sous cet angle novateur, quelques-uns des offices liturgiques composés pour les fêtes des saints les plus importants dans la province ecclésiastique de Reims illustrent parfaitement le concours croisé du facteur religieux et du facteur politique au sein des institutions ecclésiastiques aux VIII ${ }^{\mathrm{e}}$ et $\mathrm{IX}^{\mathrm{e}}$ siècles, au moment même de la grande réforme liturgique carolingienne de l'Occident latin.

Ces offices dits « historiques » relatent dans leurs chants, sous la forme de récits narratifs, la christianisation de la Gaule septentrionale, notamment lors de la période mérovingienne ${ }^{4}$. On instaure alors dans la liturgie de nouvelles fêtes propres, célébrées annuellement dans telle église, tel diocèse, telle province. Une tradition historiographique s'établit et édifie tant les clercs que les

\footnotetext{
*. - Jean-François GoudesEnNE, Chargé de recherche au CNRS, 14, rue Léonard Danel, 59800 Lille.

1. - P. Brown, Le culte des saints : son essor et sa fonction dans la chrétienté latine, Paris, 1984.

2. - Les fonctions des saints dans le monde occidental (III ${ }^{e}$-XIII ${ }^{e}$ siècles), Colloque organisé par l'École française de Rome, 27-29 octobre 1988, Rome-Paris, 1991.

3. - Pour ne citer que quelques-uns des ouvrages de ces auteurs, mentionnons les deux suivants, ouvrages collectifs : F. Dolbeau, M. Heinzelmann, J.-C. Poulin, « Les sources hagiographiques narratives composées en Gaule avant l'an mil (SHG). Inventaire, examen critique, datation », Francia, Paris, 15/1987, 1988, p. 701-731 et M. Heinzelmann (dir.), Manuscrits hagiographiques et travail des hagiographes, Sigmaringen, 1992.

4. - Cet article résulte de notre thèse de doctorat, Les offices historiques ou historiae composés pour les fêtes des saints du VIII au XI siècle dans la province ecclésiastique de Reims, Thèse de doctorat en musicologie, Université de Tours, 1996. Elle est en cours de publication chez Brepols (B-Turnhout).
} 
fidèles; elle propose à côté des textes de l'Écriture, une prise de conscience historique de l'histoire des royaumes francs. Composés à la demande d'une communauté religieuse par un ou plusieurs auteurs, parfois les hagiographes eux-mêmes ou leurs disciples, ces offices instaurent alors une tradition parallèle et autonome de Vitae, maintenue bien souvent tardivement, au-delà même du Moyen Âge (XVII ${ }^{\mathrm{e}}$, XVIII ${ }^{\mathrm{e}}$ siècles).

Après avoir rapidement présenté le cadre dans lequel ont été composés les offices historiques, nous montrerons que de nombreux centres ecclésiastiques de Belgique seconde ont développé ce «nouveau » genre littéraire et musical dans un contexte historique et politique, extrêmement favorable depuis $1 \mathrm{e} \mathrm{VI}^{\mathrm{e}}$ siècle, au culte public des saints dits « locaux ». Plusieurs types de sources manuscrites d'époques et de milieux très différents répercutent et transmettent les compositions, parfois attribuables à des auteurs célèbres comme Hilduin de Saint-Denis $(†$ 840) ou Hucbald de Saint-Amand (ca 840-ca $930)^{5}$. Les offices historiques véhiculent auprès d'innombrables générations de moines, de clercs et de fidèles, des textes et des thématiques qui chantent la mémoire des Gaules et participent à l'élaboration d'une véritable historiographie.

\section{L'instauration de fêtes propres dédiées aux saints « locaux » dans la liturgie romano-franque}

Le domaine étudié ici concerne la liturgie de l'Office divin, chanté quotidiennement, tant dans les monastères que dans les cathédrales, par les moines aussi bien que les clercs. L'Office se répartit selon les heures canoniales ou monastiques, les parties les plus développées étant les vigiles (ou matines), les vêpres et les laudes ${ }^{6}$. Il semble assez difficile de se faire une idée concrète et exacte du déroulement de la liturgie de l'Office en Gaule avant les VIII ${ }^{\mathrm{e}}-\mathrm{IX}^{\mathrm{e}}$ siècles, c'est-à-dire avant la romanisation promue par Pépin le Bref et poursuivie par les Carolingiens ${ }^{7}$. L'année liturgique est séparée en deux : le temporal et le sanctoral. À côté des grandes fêtes comme Noël, Pâques, l'Ascension, la Pentecôte et la longue série des dimanches, les fêtes des saints se célèbrent suivant le calendrier et font l'objet d'une liturgie spécifique ou ordinaire (le commun des martyrs, des confesseurs etc.). Modelés sur l'office romain mis en vigueur à l'époque de Grégoire le Grand, les antiphonaires des

\footnotetext{
5. - Y. Chartier, L'Euvre musicale d'Hucbald de Saint-Amand: les compositions et le traité de musique, (Cahiers d'Études Médiévales, cahier spécial n 5), Montréal-Paris, 1995.

6. - On se reportera à l'ouvrage de A.-G. MARTIMORT, L'Église en prière : introduction à la liturgie, Tournai, 1961, p. 822.

7. - A.-G. MARTIMORT, L'Église en prière..., p. 815. Sur la romanisation des Gaules, on consultera les articles et ouvrages de C. Vogel, notamment « Les échanges liturgiques entre Rome et les pays francs jusqu'à l'époque de Charlemagne (774-814) », Le chiese nei regni dell'Europa occidentale e i loro rapporti con Roma sino all'800. 7-13 aprile 1959. Settimane di studio del Centro italiano sull'alto medioevo, 7, Spoleto, 1960, p. 185-295.
} 
églises des Gaules ont largement suivi le calendrier romain, avec les saints alors vénérés à Rome : Étienne, les apôtres Jean, Jean-Baptiste, Jean et Paul, Pierre et Paul, André ainsi que les martyrs comme Cécile, Sébastien, Clément, Vincent, Laurent, Agnès, Agathe etc. En effet, il fut autorisé de célébrer des offices élaborés non seulement à partir de l'Écriture Sainte, mais également à partir des Acta martyrum de Rome et de la chrétienté latine ${ }^{8}$.

Entre le $\mathrm{VI}^{\mathrm{e}}$ et le VIII ${ }^{\mathrm{e}}$ siècle, les vocables basilicaux et ecclésiaux se transforment et perdent le vocable primitif pour prendre celui du saint vénéré, dont les restes sont situés sous l'autel majeur'. C'est à cette époque que les clercs continuent de rassembler et de composer les actes ou passions des martyrs, les gesta brûlés lors des persécutions de Dioclétien laissant de grandes lacunes. Alors, chaque église rédige des listes de ses saints propres et compose les premiers martyrologes et calendriers, inaugurant ainsi une forme liturgique pérenne du culte des saints, forme aux expressions variées, qui s'érige en tradition ${ }^{10}$. Peu à peu, les églises locales ont alors constitué un sanctoral propre, honorant les saints qui avaient marqué leur histoire par des offices spécifiques, adaptés sur leurs propres textes hagiographiques. Dès le VIII ${ }^{\mathrm{e}}$ siècle au moins, de nombreux saints locaux, diocésains, provinciaux ou « nationaux » enrichissent les livres liturgiques de compositions littéraires et musicales nouvelles, qui ne cesseront de fleurir durant tout le Moyen Âge ${ }^{11}$. Comme l'expose Ritva Jonsson, l'historia, que nous appelons également office historique, consiste en une série d'antiennes et de répons, rédigés à partir de textes hagiographiques antérieurs ou à partir de textes nouveaux, chantés au long des heures ${ }^{12}$. C'est Amalaire de Metz qui, vers 830, définit le premier ce genre «nouveau » de l'époque carolingienne, issu des compositions romaines établies à partir des livres historiques de la Bible aux VII ${ }^{\mathrm{e}}$ et $\mathrm{VIII}^{\mathrm{e}}$ siècles ${ }^{13}$.

S'il s'inscrit dans la continuité du grand mouvement provoqué par les nombreuses translations de reliques en Orient puis à Rome au IV siècle, le culte des saints en Occident, plus particulièrement dans les royaumes francs, revêt des aspects particuliers qui le lient aux destinées politiques de la Gaule et de ses grandes cités. Selon Luce Pietri, ce culte est avant tout « poliade »,

8. - A. Gastoué, Les origines du chant romain : l’Antiphonaire grégorien, Paris, 1907, p. 277.

9. - Art. « Saint» dans le Dictionnaire d'Archéologie Chrétienne et de Liturgie, t. 15/1, p. 420-462.

10. - Dom J. Dubois (†), J.-L. Lemaître, Sources et méthodes de l'hagiographie médiévale, Paris, 1993, chap. 3, p. 59-102.

11. - A. Gastoué, Les origines du chant romain..., p. 279-280.

12. - R. Jonsson, Historia : études sur la genèse des offices versifiés (Studia latina Stockholmiensia, 15), Stockholm, 1968, p. 12.

13. - J.-M. HANSSENS, Amalarii episcopi opera liturgica omnia (Studi e testi, 138-140), Rome, 1948-1950, III, p. 393. 
lié à l'identité même de la civitas $^{14}$ et sert de modèle aux souverains : il sacralise le pouvoir d'un roi et affermit sa dynastie. C'est par son biais que s'opère le réveil de la conscience politique de la Gaule et que s'établit l'ordre nouveau sur les ruines impériales. Les civitates, devenues évêchés au IV siècle, se placent donc sous le patrocinium d'un martyr ou d'un confesseur, érigé en protecteur de l'unité territoriale. L'épanouissement de cette composante politique dans l'hagiologie et culte liturgique correspondant se développe essentiellement au $\mathrm{VI}^{\mathrm{e}}$ siècle, pour atteindre son apogée sous les Mérovingiens, au $\mathrm{VII}^{\mathrm{e}}$ et dans la première moitié du VIII ${ }^{\mathrm{e}}$ siècle ${ }^{15}$. Ainsi, les fêtes religieuses et liturgiques dédiées au saint «patron » représentent des points forts de la vie civique $^{16}$. Il n'est pas alors étonnant que la promotion des cultes, la fondation de monastères, les droits d'exemption, les donations aient été l'objet d'enjeux de pouvoir et de rivalités à tous niveaux (épiscopal, monastique, dynastique). Les différentes dynasties royales se placent sous le vocable et la protection de saints particuliers, dont l'épanouissement et la diffusion du culte sont étroitement liés aux enjeux et aux rivalités politiques : aux $\mathrm{VII}^{\mathrm{e}}$ et $\mathrm{VIII}^{\mathrm{e}}$ siècles, lors des rivalités entre les maires du palais d'Austrasie et les rois neustriens, il y a alors concurrence entre les cultes de saint Remi, de saint Médard et de saint Denis. Le premier est très favorisé par les maires austrasiens, le second est encouragé par les rois mérovingiens depuis Clotaire I ${ }^{\text {er }}$; le troisième enfin est le patron de la lignée neustro-burgonde ${ }^{17}$.

Bien qu'il n'y ait plus de nombreuses figures de sainteté après le milieu du VIII ${ }^{\mathrm{e}}$ siècle $^{18}$, le patronage dynastique entrepris par les Mérovingiens se poursuit sous les Carolingiens, dans la mesure où ces derniers favorisent les saints qui ont joué un rôle dans l'établissement des églises de leur royaume ${ }^{19}$. Leur culte fait l'objet de choix selon plusieurs critères : la multiplication de saints locaux depuis le $\mathrm{VII}^{\mathrm{e}}$ siècle conduit Charlemagne à interdire en 789 le culte des saints inconnus. À partir de 794, seuls les saints qui ont reçu une vita ou une passio sont « habilités » à faire l'objet d'une vénération publique et liturgique $^{20}$. Le patrocinium auprès des rois et empereurs tel Pépin le Bref, placé

14. - Il s'agit d'une terminologie proposée par L. Pietri, pour signifier les aspects à la fois symboliques, identitaires et politiques du culte des saints mérovingiens : « (...) culte que l'on pourrait qualifier de 'poliade' puisqu'il s'accompagne de la conviction que le martyr ou le confesseur a été dévolu à la cité par la Providence divine ». L. PIETRI, «Culte des saints et religiosité politique dans la Gaule du V $\mathrm{V}^{\mathrm{e}}$ et du VI ${ }^{\mathrm{e}}$ siècle », Les fonctions des saints..., p. 355-356.

15. - Ibid., p. 353.

16. - Ibid., p. 357.

17. - Ibid., p. 361-362.

18. - P. Riché, « Les carolingiens en quête de sainteté », Les fonctions des saints dans le monde occidental (III'-XIII ${ }^{e}$ siècles), Colloque organisé par l'École française de Rome, 27-29 octobre 1988, Rome-Paris, 1991, p. 225-240.

19. - P. RICHÉ (dir.), Histoire des saints et de la sainteté chrétienne, t. IV (les voies nouvelles de la sainteté, 605-814), Paris, 1986, p. 33.

20. - Ibid., p. 33. 
sous la protection de ce chef de la légion thébaine et archimartyr des Gaules saint Maurice, de Louis le Pieux puis de Charles le Chauve, se poursuit comme précédemment avec les rois mérovingiens. Ainsi, le caractère exceptionnel de l'antiphonaire personnel de Charles le Chauve, daté des environs de 870, assez singulier dans l'histoire des textes liturgiques du haut Moyen Âge par le nombre d'offices de saints gallicans qu'il contient, est-il une des conséquences directes de la continuation de cette vénération officielle des patrones des dynasties franques, commencée par Clotaire et Dagobert aux $\mathrm{VI}^{\mathrm{e}}$ et $\mathrm{VII}^{\mathrm{e}}$ siècles.

Le développement des cultes de saints, tant dans les fondations royales les basiliques martyriales - que dans les monastères épiscopaux, se réalise dans une double relation entre ce lieu de culte et la cathédrale voisine. S'il est parfois difficile de définir la part respective des deux types d'institutions ecclésiastiques dans la promotion du culte, elles ont souvent exercé des rôles complémentaires. L'exemple le plus célèbre des Gaules est saint Martin à Tours, qui prend naissance dans la communauté monastique de la basilique, mais qui est surtout promu par les évêques de Tours. Ce cas de figure est maintes fois représenté par d'autres saints : Remi à Reims, Éloi à Noyon... Bien qu'inhumé à Noyon, cité de son épiscopat, c'est à Soissons que le corps de saint Médard est transféré vers 560, sur l'instigation du roi Clotaire ${ }^{\mathrm{er}}$, en quelque sorte le fondateur de l'abbaye qui deviendra Saint-Médard de Soissons $^{21}$. Le culte résulte de la volonté personnelle d'un roi souhaitant mettre toute sa dynastie sous la protection du saint. À Reims, le culte de saint Remi est partagé entre les moines et l'évêque, Saint-Remi de Reims, fondé vers 550, étant un des premiers monastères épiscopaux de la province. Il s'agit d'un monastère de clercs sur lequel l'évêque a droit de regard. Sous Ebbon et surtout Hincmar, c'est la cathédrale qui prend l'initiative du renouveau et de la promotion liturgique du culte ${ }^{22}$. À Beauvais, si le tombeau de saint Lucien a suscité un culte martyrial promu par une communauté de clercs placés sous l'autorité de l'évêque avant les invasions barbares ${ }^{23}$, c'est plutôt par la volonté conjointe du roi Childebert ${ }^{\text {er }}$ et de l'évêque de Beauvais qu'est nouvellement fondé le monastère Saint-Lucien, vers 560²4. Au

21. - D. DefENTE (dir.), Saint-Médard, trésors d'une abbaye royale, Paris, 1996, p. 43.

22. - J. Devisse, Hincmar, archevêque de Reims (845-882), Genève, 1976, p. 1004 et sqq. Au temps de l'historiographe Flodoard, au $\mathrm{X}^{\mathrm{e}}$ siècle, Saint-Remi est considérée comme une création de Remi. L'évêque et l'abbé, parfois confondus dans le même personnage, y constituent, tout comme dans les monastères voisins de Hautvilliers et de Saint-Basle, une sorte de couple, exemplaire par leurs rapports équilibrés et féconds en terme de juridiction ecclésiastique. Voir à ce sujet M. SoT, Un historien et son Église au X $X^{e}$ siècle : Flodoard de Reims, Paris, 1993, 228 et sqq.; «La fonction du couple saint évêque saint moine dans la mémoire de l'église de Reims au $\mathrm{X}^{\mathrm{e}}$ siècle », Les fonctions des saints dans le monde occidental..., p. 239-240.

23. - DeletrRÉ, Histoire du diocèse de Beauvais depuis son établissement au III e siècle, Beauvais, 1842, p. 123,193 et 198 .

24. - Ibid., p. 195 et sqq. 
$\mathrm{VII}^{\mathrm{e}}$ siècle à Arras, c'est encore cet ancien type de culte qui prévaut pour l'évêque saint Vaast, qui n'est pas fondateur : inhumé dans l'église d'Arras, son corps aurait été transféré en 667 par son septième successeur Aubert, assisté par Omer, évêque de Thérouanne, dans une chapelle dédiée à saint Pierre, qui devient bientôt l'église de Saint-Vaast, largement dotée par Thierry $\mathrm{III}^{25}$. Pour saint Nicaise, on sait très peu de choses sur les rôles respectifs de l'abbaye du même nom et la cathédrale ${ }^{26}$. Quant aux évêques Vaast, Géry, Lucien, s'ils n'ont pas fondé directement de monastère, la translation de leur corps a justifié la création d'une abbaye voisine de la cathédrale. Thierry, disciple de saint Remi, fonde lui-même vers 508 le premier monastère de la province, le Mont d'Hor ${ }^{27}$. Autour d'Éloi à Noyon se constitue à sa mort une communauté monastique vers 660 . Mais c'est surtout l'action personnelle de confesseurs qui instaura de nombreuses abbayes. Le plus célèbre est Amand, véritable apôtre de l'actuelle Belgique ${ }^{28}$. On lui doit Elnone vers 636, qui prendra son nom plus tard, Saint-Pierre (le Mont Blandin ou Blandinium) et Saint-Bavon de Gand, Nivelles, Barisis-aux-Bois et peut-être encore d'autres monastères tant à l'intérieur qu'en dehors de la province de Reims $^{29}$. Ainsi la province de Reims compte-t-elle au début du VIII ${ }^{\mathrm{e}}$ siècle un nombre de monastères des plus considérables parmi toutes les provinces du royaume des Francs ${ }^{30}$.

Insistons donc sur le fait qu'entre le $\mathrm{IV}^{\mathrm{e}}$ et le $\mathrm{IX}^{\mathrm{e}}$ siècle, le culte liturgique des saints les plus importants et les plus anciens dans la province de Reims ne résulte pas exclusivement du monachisme mais bien du concours conjoint de plusieurs communautés, monastiques et cathédrales ${ }^{31}$.

25. - Dom L.-H. CotTIneau, Répertoire topo-bibliographique des abbayes et prieurés, Mâcon, 1939, p. 161 ; P. Bougard (dir.), Histoire d'Arras, Dunkerque, 1988, p. 28-30.

26. - M. Sot, Un historien et son église..., p. 372-375; dom BAudot et dom Chaussin, La vie des saints et bienheureux selon l'ordre du calendrier avec l'histoire des fêtes, Paris, 1935-1956, vol. 12 (14 déc.), p. 439.

27. - Dom J. Hourlier, « Le monastère de Saint-Thierry aux époques mérovingienne et carolingienne », Saint-Thierry, une abbaye du VIe au XX siècle, Reims/Saint-Thierry, 1979, p. 21.

28. - Voir la place que lui accorde E. de Moreau : « une histoire de l'Église en Belgique doit lui faire une large place, car aucun apôtre n'a contribué autant que lui à rendre ce pays chrétien »; E. DE Moreau, Histoire de l'Église en Belgique des origines aux début du XIIe siècle, Bruxelles, 1940, p. 73, 89; H. Platelle, Le temporel de Saint-Amand, Librairie d'Argences, Paris, 1962, p. 33.

29. - Marchiennes, Hamage, Maubeuge, Lobbes, Saint-Ghislain etc., voir H. Platelle, ibid., p. 34-35.

30. - Plus de quarante monastères ont été fondés entre 625 et 700 dans les seuls diocèses de Thérouanne, Tournai, Cambrai et Liège; voir S. LEBECQ, Les origines franques ( $V^{e}-I X^{e}$ siècles), Seuil (Points histoire), Paris, 1990, p. 160.

31. - On a sous-estimé le rôle des cathédrales dans l'élaboration des cultes liturgiques avant l'an mil. Par exemple, G. Duby, Le temps des cathédrales, Paris, 1966, présente d'abord le monastère dans la partie chronologique antérieure (980-1140) puis la cathédrale dans la partie suivante (11401280) et n'insiste pas du tout sur le rôle des cathédrales dans les premiers siècles de l'expansion chrétienne après Constantin. 


\section{Les historiae dans les sources liturgiques}

Comme le fit remarquer monseigneur Lesne,

« les églises épiscopales et monastères de la province ecclésiastique de Reims figurent pour la plupart parmi les établissements les mieux pourvus en livres dans la période qui s'étend du $\mathrm{VIII}^{\mathrm{e}}$ au XI $\mathrm{XI}^{\mathrm{e}}$ siècle $»^{32}$.

En ce qui concerne l'antiphonaire de l'Office grégorien ou romano-franc, la province de Reims est de toutes les grandes provinces d'Europe, celle qui en conserve à ce jour le plus grand nombre et non des moindres. Rappelons qu'un nombre important de ses sources liturgiques et musicales constituent une part non négligeable des éditions monumentales comme le Corpus Antiphonalium Officii, la Paléographie Musicale ou encore l'Antiphonale Missarum Sextuplex ${ }^{33}$.

Comme dans la plupart des régions d'Europe, les sources de l'Office sont plus rares que celles de la Messe. Elles sont constituées de deux types principaux de livres liturgiques : d'une part l'antiphonaire et le bréviaire; d'autre part, le lectionnaire et le recueil hagiographique. Un certain nombre de sources telles que le lectionnaire de Corbie qui contient quelques Vitae et Passions des saints de la province ${ }^{34}$, daté des environs de 800 , peuvent être considérées comme des sources indirectes des plus anciennes pour les historiae. Ces dernières ont été adaptées à partir de ces vitae d'abord oralement, puis par écrit ${ }^{35}$. Leur présence aux siècles suivants, dans certains recueils où elles sont intercalées entre les différentes vitae, semble constituer un prolongement de cette tradition, qui s'est fixée progressivement à l'intérieur du livre et a ainsi donné naissance au libellus hagiographique et musical carolingien.

Quant aux premières sources directes des offices des saints, apparues après des décennies de pratique orale sur les textes des passiones ou vitae, elles ne remontent guère au-delà des $\mathrm{IX}^{\mathrm{e}}$ et $\mathrm{X}^{\mathrm{e}}$ siècles. Les témoins subsistants sont le plus souvent des copies plus luxueuses de libelli antérieurs, disparus ou détruits. Rappelons qu'il ne subsiste aujourd'hui, qu'à peine $10 \%$ des livres liturgiques des bibliothèques ecclésiastiques médiévales en Europe occidentale $^{36} \ldots$

32. - $\mathrm{M}^{\mathrm{gr}} \mathrm{E}$. LESNE, Les livres, scriptoria et bibliothèques du commencement du VIII siècle à la fin du XII siècle (Histoire de la propriété ecclésiastique en France, t. 4), Lille, 1938, p. 599.

33. - Est-il nécessaire, pour souligner cet aspect, de rappeler que le graduel de la cathédrale de Laon, les antiphonaires de Charles le Chauve, de Noyon (Mont-Renaud), du Mont-Blandin, de Corbie et de Senlis ou encore de Durham émanent tous de ce même espace ecclésiastique? Dom R.-J. HesBert, CAO et Antiphonale Missarum Sextuplex, Rome, 1935.

34. - BNF lat. 12598 (Vies des saints Vaast, Fuscien, Victoric et Gentien, etc.).

35. - Voir à ce sujet R. Jonsson, Historia..., op. cit. (n. 12), p. 177-178.

36. - M. Huglo, Les livres de chant liturgique (Typologie des sources du Moyen Âge occidental, 52), Turnhout, 1988, p. 137. 


\section{Les recueils hagiographiques}

Parce qu'étroitement liées au caractère local d'un culte, les historiae ont d'abord été consignées dans un type de manuscrit très spécifique, qui dérive à la fois du lectionnaire (ou passionnaire) et du libellus hagiographique : le recueil hagiographique. Il constitue sans aucun doute « le » livre du trésor des monastères et rassemble dans une somptueuse décoration la Vita et les Miracula d'un ou de plusieurs saints fondateurs. Les historiae y sont rédigées avec ou sans notation musicale, à la suite de la Vita ou avant les Miracula. S'y adjoignent divers textes hagiographiques comme de nouvelles vies en vers, des poèmes rythmiques, des sermons, des récits de relation ou de translation etc. Il s'agit à strictement parler de recueils hagiographiques plus que de libelli $^{37}$. Avec une dizaine de témoins connus à ce jour, Reims et ses grandes institutions ecclésiastiques intra et extra muros semblent avoir exercé une activité particulièrement importante dans la production de ce type de recueils ${ }^{38}$.

Le recueil de Saint-Thierry de Reims conservé au Vatican ${ }^{39}$ est un des plus anciens et des plus importants : il rassemble à la fois des textes hagiographiques et des offices de plusieurs saints patrons vénérés au monastère : Barthélemy, Thierry, Amand, Gervais et Protais etc. Selon dom Wilmart, il fut commencé par un premier scribe au $\mathrm{X}^{\mathrm{e}}$ siècle, et poursuivi par un second puis un troisième à la fin du siècle ou peu après l'an mil ${ }^{40}$. C'est au fondateur du monastère, saint Thierry, que revient la place d'honneur. La partie le concernant commence justement par sa liturgie, en l'occurrence, l'Épître dédicatoire du maître et écolâtre Hucbald de Saint-Amand aux moines de Saint-Thierry, rédigée à l'occasion de la composition de l'office du saint patron $\left(\mathrm{f}^{\circ} 25-25 \mathrm{v}^{\circ}\right)$. Ont été ajoutées au XII ${ }^{\mathrm{e}}$ siècle deux hymnes d'Hucbald ( $\mathrm{f}^{\circ}$ 26), probablement pour remplir l'espace blanc qui précède le début de la Vita ( $f^{\circ}$ 26v-60), suivies de récits de miracles et d'écrits divers sur l'histoire du monastère $\left(\mathrm{f}^{\circ} 60 \mathrm{v}^{\circ}-65 \mathrm{v}^{\circ}\right)$. Deux autres historiae complètent le recueil : celles des saints martyrs milanais Gervais et Protais $\left(f^{\circ} 78 v^{\circ}-82 v^{\circ}\right.$ ), dont les reliques semblent avoir été apportées au monastère, puis saint Amand ( $\mathrm{f}^{\circ} 101-103 \mathrm{v}^{\circ}$ ), dont le culte semble s'expliquer par les relations privilégiées qui se sont établies avec l'abbaye d'Elnone depuis le séjour d'Hucbald au monastère pour la restauration des écoles rémoises et du culte de saint

37. - Ibid., p. 71-73 : « [ces recueils] procèdent évidemment d'anciens libelli, mais ne sauraient être considérés comme tels dans leur état actuel ».

38. - J.-F. GOUdESENNE, Les Offices historiques..., op. cit. (n. 4), t. I, p. 84-87.

39. - Reginensis lat. 466.

40. - Dom A. WiLmart, Codices Reginenses latini, Bibliotheca Vaticana, 1945, t. II, p. 624-625. Voir également : H. EHRENSBERGER, Libri Liturgici Bibliothecae Apostolicae Vaticanae manuscripti, Friburg, 1897, p. 64 et B. KRUSCH, MGH, Scriptores Rerum Merovingicarum, t. V, p. 414. 
Thierry vers $900^{41}$. La notation musicale neumatique, propre à Saint-Thierry, en fait un monument de la paléographie musicale occidentale ${ }^{42}$ (fig. 2).

Après les écoles de Reims, c'est l'abbaye de Sithiu ou Saint-Bertin qui détient le plus grand nombre d'anciens recueils hagiographiques. Le recueil de l'abbé Odbert (986-1007) est un véritable chef-d'œuvre, dédié au saint patron Bertin, à ses disciples Mommelin, Ebertramme et Winoc, sans oublier l'évêque Omer, à l'origine première de la mission luxovienne en Morinie ${ }^{43}$. Le recueil s'ouvre avec deux grandes miniatures à pleine page ( $f^{\circ} 2 v^{\circ}$ et 3 ) représentant les saints dans des décors d'architecture monastique, de drapés dans un style antiquisant et des animaux fantastiques. De la Secunda Vita des saints Omer, Bertin et Winoc ${ }^{44}$, le recueil ne donne que les chapitres concernant saint Bertin, tout d'abord le prologue $\left(f^{\circ} 3 v^{\circ}-6\right)$. S'ensuit une nouvelle vie métrique ( $\left.\mathrm{f}^{\circ} 7 \mathrm{v}^{\circ}-28\right)$, attribuée par Morand à l'entourage intellectuel du moine calligraphe Guntbert (milieu du IX ${ }^{\mathrm{e}}$ siècle) $)^{45}$, puis deux hymnes et une messe propre pour la fête du saint $\left(\mathrm{f}^{\circ} 28 \mathrm{v}^{\circ}-30\right)$. Revient ensuite la Secunda vita, à laquelle s'enchaînent les récits de miracles ( $\left.\mathrm{f}^{\circ} 32 \mathrm{v}^{\circ}-69\right)$. C'est immédiatement après un sermon anonyme $\left(f^{\circ} 69 \mathrm{v}^{\circ}-73\right)$, sans aucun espace blanc intermédiaire, que commence la rubrique de l'office en lettres vermillon pour la fête de la déposition ( $\mathrm{f}^{\circ} 73-76$ ), suivi de la fête de la translation ( $\mathrm{f}^{\circ}$ 76-78), avec notation musicale neumatique en notation française de type «bertinien ».

Le liber miraculorum sancti Vedasti (fig. 3), postérieur d'une trentaine d'années au recueil précédent, est un magnifique fleuron de la grande renaissance du scriptorium vedastin sous l'abbatiat de Léduin $(1018-1040)^{46}$.

41. - Y. Chartier, L'Euvre musicale d'Hucbald..., op. cit. (n. 5), p. 19.

42. - On remarquera dans cet important recueil que les saints patrons les plus illustres du monastère n'ont pas reçu d'historia ou d'office, ce qui paraît assez surprenant. L'examen codicologique du manuscrit semble confirmer l'hypothèse de la présence d'offices placés avant chaque vita: en effet, chaque début de vita ou de passio, que ce soit pour Barthélemy, Thierry ou Théodulphe, commence par une lacune du texte et indique des feuillets ou des quaternions manquants. Il semblerait logique que l'Épître dédicatoire d'Hucbald, annonçant très solennellement la composition d'une série d'antiennes et de répons pour saint Thierry, eût été suivie ou précédée au moins par le texte de cet office au cas où le notateur n'aurait pas eu le temps d'écrire les neumes. De même, la présence fréquente de l'office de saint Barthélemy dans d'autres manuscrits liturgiques plus tardifs de l'abbaye confirme cette probabilité. Sur la notation neumatique voir Dom J. HourLIER, « Le Domaine de la notation messine », Revue grégorienne, t. XXX, 1951; P. WAGNER, Neumenkunde : Palaeographie des Gregorianischen Gesanges, Friburg, 1905, p. 126-128.

43. - Boulogne-sur-Mer, BM, ms 107; la notice assez récente de Van der Straeten, 1971, p. 137138 est peu détaillée; on se reportera plutôt à celle de Holder-Egger dans les MGH, Scriptores, t. $15 / 1$, p. 508 .

44. - La Vita des trois saints forme un seul tout.

45. - F. MORAND, «Vita sancti Bertini metrica prior ab anonymo auctore conscripta », Mélanges historiques, Paris, 1873, p. 2-41.

46. - Arras, BM, ms 734 ; D. EsCUDIER, Le scriptorium de Saint-Vaast d'Arras des origines au XII ${ }^{e}$ siècle (contribution à l'étude des notations neumatiques du Nord de la France), Thèse pour le diplôme d'archiviste-paléographe, École Nationale des Chartes, Paris, 1969, p. 231-235. Une autre 


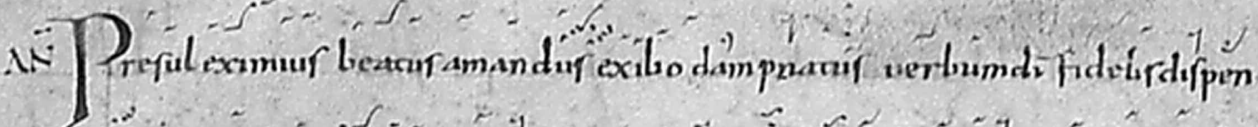

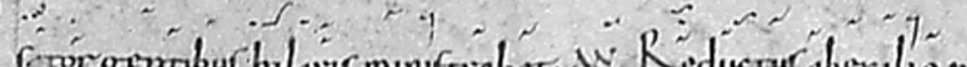

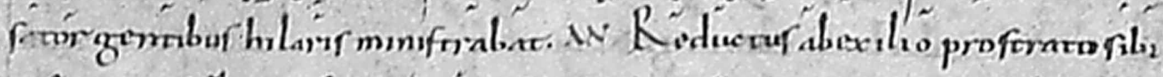

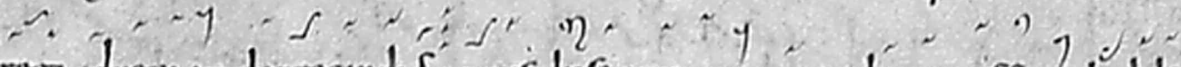

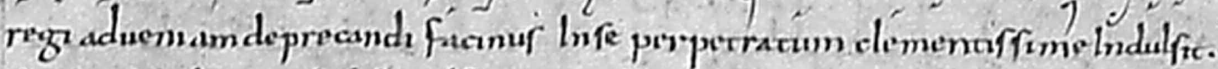

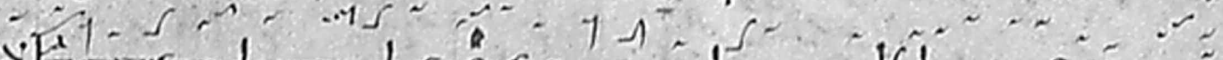

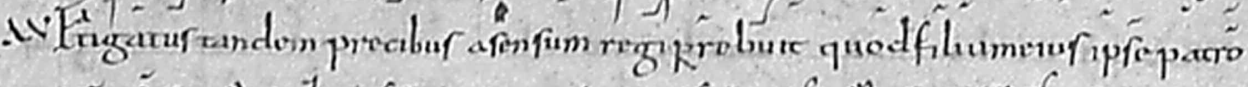

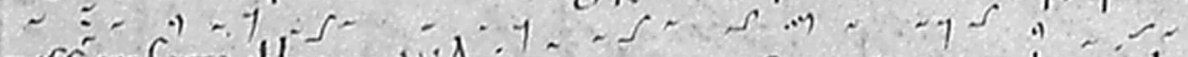

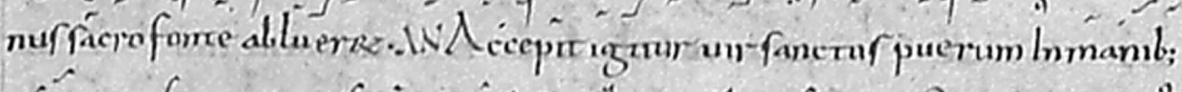

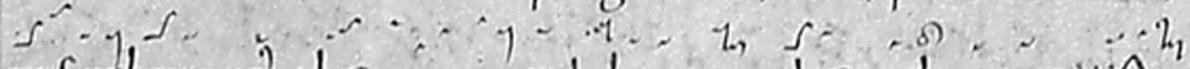

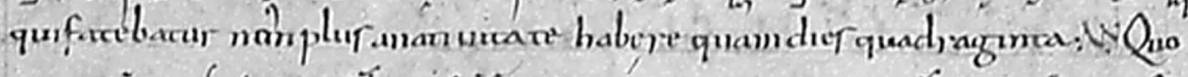

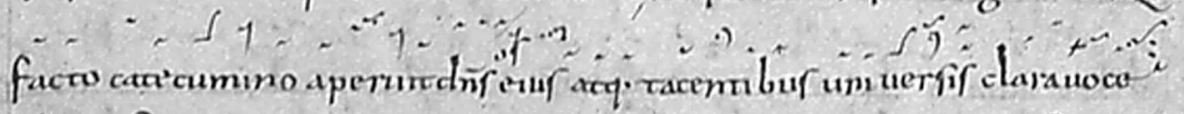

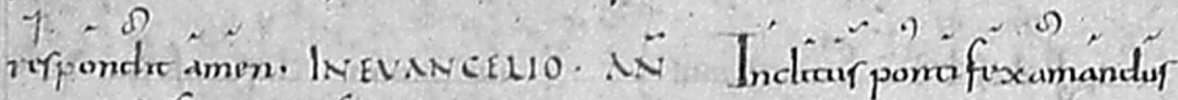

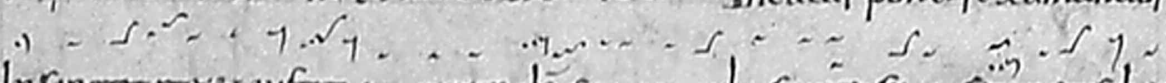

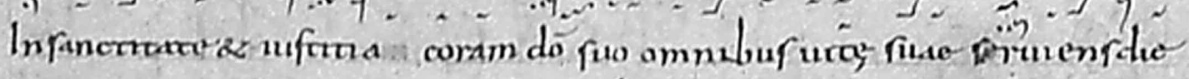

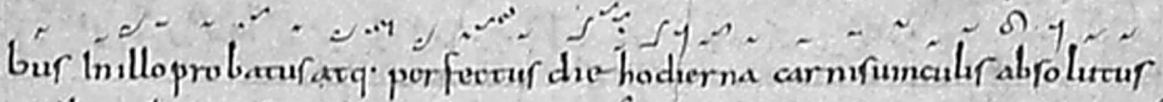

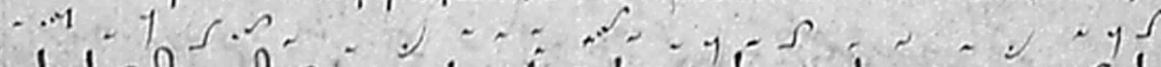

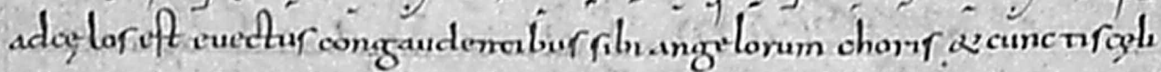

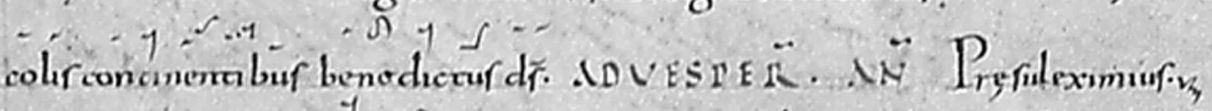

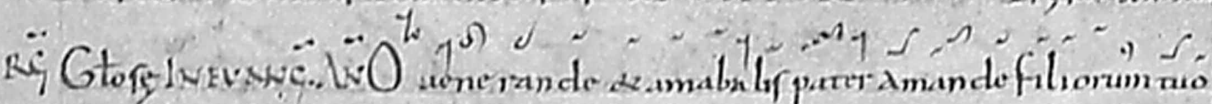

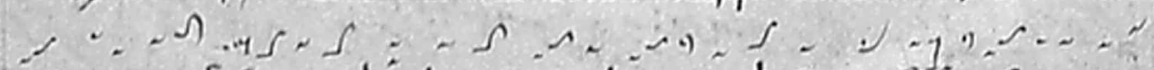

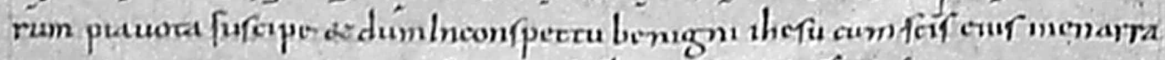

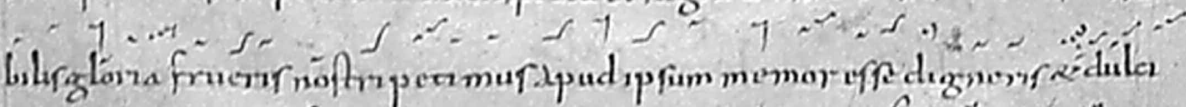

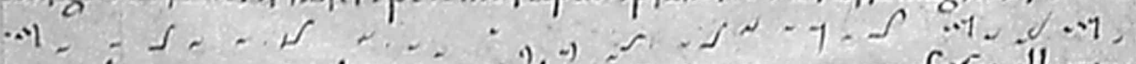

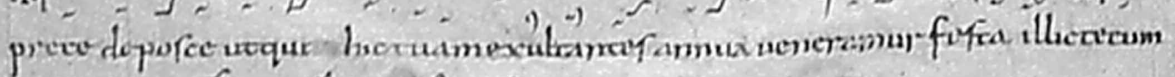
moramuf for habere comanua.

Fig. 2. - Recueil hagiographique de Saint-Thierry de Reims (fin $X^{e}$ s.). Office de saint Amand : les laudes avec narration du baptême de Sigebert III. Notation en neumes de Saint-Thierry de Reims. Biblioteca Apostolica Vaticana, Reg. Lat. 466, f $103 \mathrm{v}^{\circ}$. Cliché : BAV. 


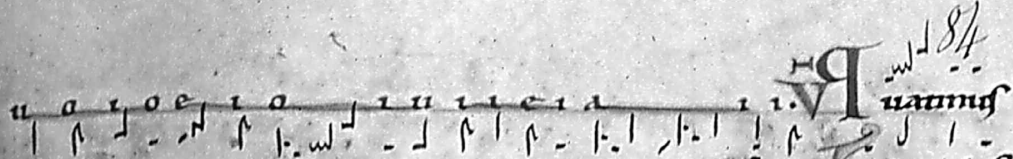

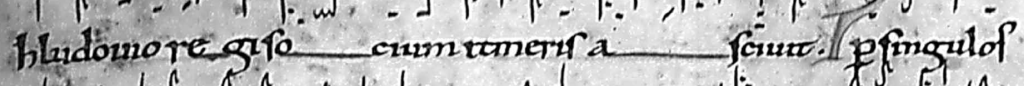

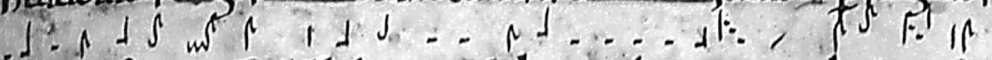

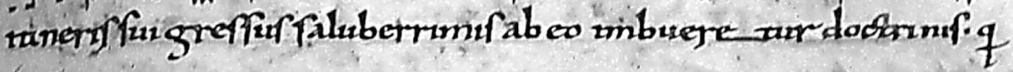
(

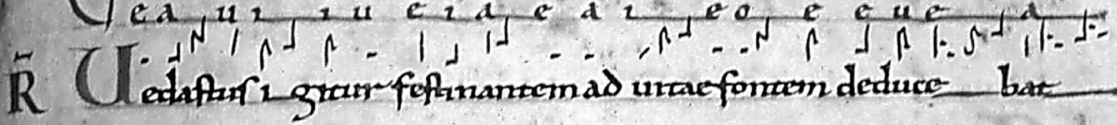

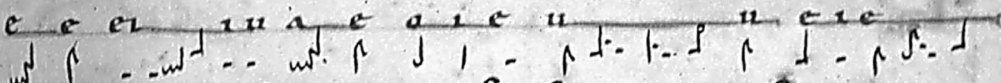
regom remigur aurpemponafex fum martuenton

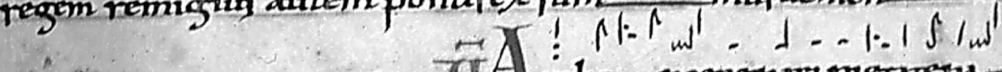

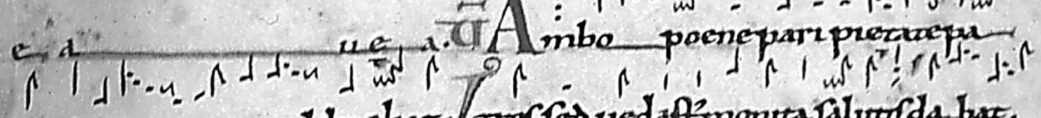
arma

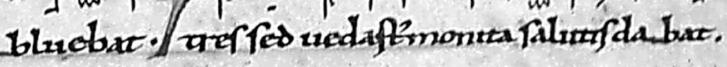

入

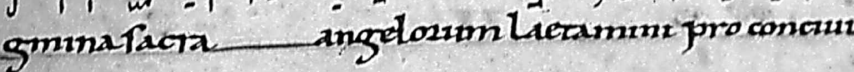

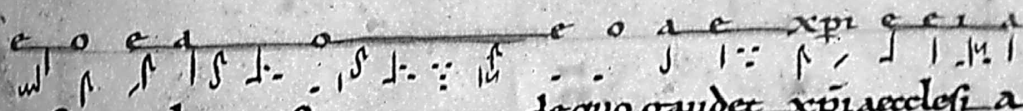
uefroveda dequo gaudec xpiacedefi a

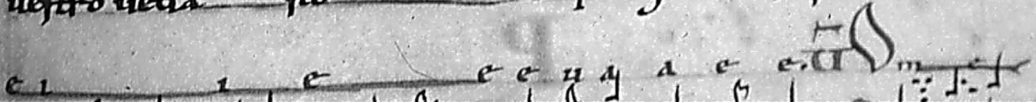

Fig. 3. - Recueil hagiographique de Saint-Vaast d'Arras, dit « Liber miraculorum » d'Albert (vers 1030). Arras, BM, 734, fo 84.

Répons de l'office de saint Vaast «Vedastus igitur», évoquant le baptême de Clovis. Cliché de l'auteur. 
Entièrement copié, calligraphié et enluminé par un certain Albert, moine de Saint-Vaast, scribe, enlumineur et notateur, dont on trouve au folio 6 le colophon en lettres d'or insérées dans un tapis d'entrelacs noirs et blancs sur fond vert : Albertus scripsit, le manuscrit date de la première moitié du $\mathrm{XI}^{\mathrm{e}}$ siècle, au plus tard de $1050^{47}$. L'office de saint Vaast (déposition et octave), pourvu d'une notation neumatique française, de type védastin, vient à la suite de plusieurs textes hagiographiques : la Vita d'Alcuin, récrite sous l'abbatiat de son ami Radon aux alentours de 800, remaniement de la Vita de Jonas de Bobbio du VII ${ }^{\mathrm{e}}$ siècle; elle est immédiatement suivie d'un sermon du même Alcuin, puis des récits de miracles rédigés par l'écolâtre Haimond d'Arras et des auteurs anonymes; ensuite, le récit de la translation à Beauvais et de la relation des reliques du saint à la fin $\mathrm{du} \mathrm{IX}^{\mathrm{e}}$ siècle, à la suite des invasions normandes. Ces nouvelles fêtes ont encore suscité de nouveaux récits de miracles. C'est après un feuillet et demi blanc que commencent les compositions liturgiques : cinq hymnes pour saint Vaast et une hymne pour saint Remi (f $77 \mathrm{v}^{\circ}-81$ ). L'office occupe les $\mathrm{f}^{\circ} 81 \mathrm{v}^{\circ}-89$. Il est suivi après un demi-feuillet blanc par d'autres compositions d'Alcuin, notamment des vers destinés à être inscrits au tombeau du saint patron ainsi qu'aux autels des divers saints dans l'abbatiale et les différentes églises de l'abbaye.

\section{Les livres de l'Office : antiphonaires et bréviaires}

Une fois consignés dans des libelli ou des recueils hagiographiques, c'est ensuite dans les livres de chœur et tout spécialement dans les antiphonaires puis les bréviaires que l'on introduit les nouveaux offices. Ce phénomène s'explique d'une part par la volonté d'intégrer un office particulier dans le cycle annuel de la liturgie, et d'autre part par le souci de le diffuser dans les livres liturgiques des églises voisines.

Les antiphonaires sont très peu nombreux et leur proportion est statistiquement infime par rapport à l'ensemble des livres liturgiques ${ }^{48}$. Les vestiges antérieurs au $\mathrm{X}^{\mathrm{e}}$ siècle sont extrêmement rares et exceptionnels et il n'en reste bien souvent que quelques témoignages indirects dans la littérature et les chroniques. Au VIII ${ }^{\mathrm{e}}$ siècle, le pape Paul $\mathrm{I}^{\mathrm{er}}$ envoie au roi Pépin le Bref un antiphonaire et un livre de répons ${ }^{49}$. Au IX ${ }^{\mathrm{e}}$ siècle, une anecdote fameuse rapporte que le monastère de Corbie était entré en relation avec l'Italie à partir du VIII ${ }^{\mathrm{e}}$ siècle, grâce aux voyages de ses abbés ad limina. Wala rapporte alors de Rome quatre antiphonaires que le liturgiste Amalaire de Metz vient consulter

\footnotetext{
46. - (suite) version de l'office de saint Vaast est donnée dans le manuscrit de Douai 857, également du XI ${ }^{\mathrm{e}}$ siècle, à l'usage de l'abbaye de Marchiennes, au diocèse d'Arras.

47. - Ibid., p. 231.

48. - Voir l'introduction du CAO.

49. - D'après Walafrid Strabon; voir M ${ }^{\mathrm{gr}}$ E. LESNE, Les livres, scriptoria et bibliothèques..., op . cit. (n. 32), p. 67 et K. LEVy, Gregorian Chant and the Carolingians, Princeton University, 1998, p. 31.
} 
pour la rédaction de son Liber de ordine antiphonarii ${ }^{50}$. À cette époque d'ailleurs, l'antiphonarium peut aussi bien désigner la Messe que l'Office. Pour l'abbaye de Sithiu (Saint-Bertin), le cartulaire de Folquin du $\mathrm{x}^{\mathrm{e}}$ siècle rapporte qu'un certain Guntbert de Saint-Bertin, moine copiste de l'époque carolingienne, restaure la bibliothèque du monastère et copie des livres dont trois antiphonaires pour les trois églises respectives de Saint-Bertin, SaintOmer et Saint-Winoc :

« Parce qu'il était formé comme scribe, il rénova par son savoir-faire la bibliothèque de ce monastère, qui était presque entièrement défectueuse et vétuste. De plus, il l'augmenta par d'autres volumes parmi lesquels deux antiphonaires qu'il a copiés lui-même de sa propre main; il donna l'un à Saint-Omer, l'autre à Saint-Winoc. Il en écrivit un troisième, lequel il expliqua (elucidavit) par un travail plus lucide son début et il en décora magnifiquement de lettres d'or pour les chants des grandes solennités. Parce que plus élégant, il le décerna à Saint-Bertin ... $\gg^{51}$.

Même aux $\mathrm{XII}^{\mathrm{e}}$ et XIII ${ }^{\mathrm{e}}$ siècles, période où la production des livres croît d'une manière exponentielle, il ne reste que trois ou quatre témoins complets. Plusieurs exemplaires des $\mathrm{XV}^{\mathrm{e}}$ et $\mathrm{XVI}^{\mathrm{e}}$ siècle, réalisations très luxueuses, ont été mieux conservés, probablement parce que leur usage de la notation carrée pouvait encore convenir aux clercs et aux moines des XVII et XVIII ${ }^{\mathrm{e}}$ siècles.

Le monument complet le plus ancien contenant l'antiphonaire de la Messe et de l'Office est l'antiphonaire dit de Charles le Chauve, autrefois appelé Compendiensis, réalisé au scriptorium de l'abbaye de Saint-Médard de Soissons dans les années $860-870^{52}$. Dans son introduction au $C A O$, dom Hesbert avait mentionné que le sanctoral de cet antiphonaire était un des seuls à renfermer un nombre aussi important d'offices régionaux ou locaux ${ }^{53}$. Ce livre exceptionnel atteste donc indiscutablement la formidable et précoce expansion des historiae comme genre littéraire, liturgique et musical dès le $\mathrm{IX}^{\mathrm{e}}$ siècle ${ }^{54}$. L'office de saint Médard ( $\left.\mathrm{f}^{\circ} 65 \mathrm{v}^{\circ}-66 \mathrm{v}^{\circ}\right)$ est mis au premier plan

50. - Ibid., p. 69; édition du Liber de ordine antiphonarii par Hanssens, op. cit.

51. - D'après le cartulaire de Folquin ( $\mathrm{x}^{\mathrm{e}}$ siècle), premier livre, chapitre 61 de Guntberto, dans M. GuÉRARD, Cartulaire de l'abbaye de Saint-Bertin, Paris, 1840, p. 79-80.

52. - BNF lat. 17436. Sur cet antiphonaire : M. HugLo, « Observations codicologiques sur l'antiphonaire de Compiègne (Paris, BN lat. 17436) », De Musica et Cantu : Studien zur Geschichte der Kirchenmusik und der Oper; Helmut Hucke zum 60. Geburtstag, éd. Peter Cahn et Ann-Katrin Heimer, Hildesheim, 1993, p. 117-130; Patrol. Lat., t. 78 (Saint Grégoire), p. 725-850 (éd.); B. StÄBleIN, «Antiphoner », Die Musik in Geschichte und Gegenwart. Allgemeine Enzyklopädie der Musik, F. Blume (dir.), Kassel, 1949-1968 [dans la liste chronologique] ; R.-J. HESBERT, CAO, vol. I 'cursus romanus', Rome, 1965 [un des six antiphonaires choisis pour l'édition du $C A O$ ]; R. Jonsson, Historia ..., op. cit. (n. 12), p. 30-31 ; C.C. BARBER, Codex Compendiensis, dissertation, Univ. of Oxford, 1972 (éd.); M. Huglo, « Antiphoner », The New Grove Dictionary of Music and Musicians, S. Sadie (dir.), $6^{\mathrm{e}}$ éd., London, 1980.

53. - CAO, cursus romanus, introduction, p. XVIII-XIX.

54. - R. Jonsson, Historia..., op. cit. (n. 12), p. 30-76; cet antiphonaire y fait l'objet d'un développement important. 


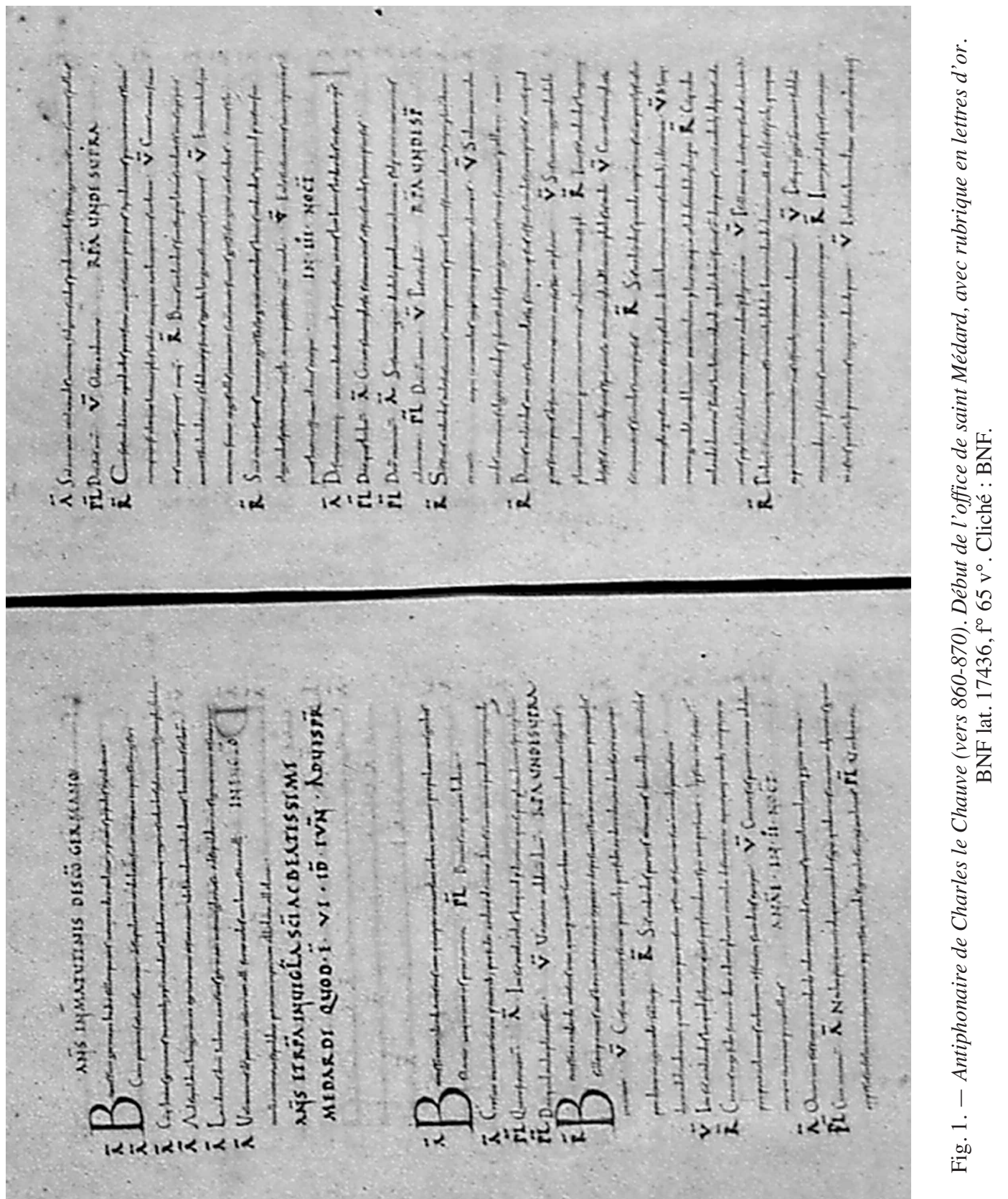


avec son titre calligraphié en lettres d'or (fig. 1), le seul du sanctoral, les rubriques pour les autres saints étant de couleur vermillon. On se souvient en effet que Charles le Chauve a reconnu en cet ancien évêque de Noyon le véritable patron de la dynastie royale depuis que Clotaire ${ }^{\text {er }}$ fit transférer ses reliques de Noyon à Soissons ${ }^{55}$. Les autres offices du sanctoral nous renseignent sur les relations entre Soissons et les autres églises de la province à l'époque carolingienne : saint Vaast ( $\mathrm{f}^{\circ} 78 \mathrm{v}^{\circ}-79$ ) se retrouve probalement dans ce livre parce que Charles le Chauve avait été lui-même abbé de Nobiliacum ou Saint-Vaast d'Arras ${ }^{56}$; le copiste du Compendiensis laisse ici un grand espace blanc sur les $f^{\circ} 78 \mathrm{v}^{\circ}$ et 79 ; saint Denis et ses compagnons Rustique et Éleuthère ( $f^{\circ} 79-80 v^{\circ}$ ), présente un des rares offices locaux d'origine franque ou gallicane romanisé à être entré dans le sanctoral universel avec les offices de saint Martin et de saint Maurice ${ }^{57}$; l'office des saints Crépin et Crépinien $\left(\mathrm{f}^{\circ} 80 \mathrm{v}^{\circ}-81 \mathrm{v}^{\circ}\right)$ provient de la cathédrale de Soissons qui conserve leurs reliques; enfin, celui de saint Quentin ( $\left.f^{\circ} 81 \mathrm{v}^{\circ}-82\right)$ provient de la basilique d'Augusta Vermanduorum, devenue abbaye; placé la veille de la fête de la Toussaint, instaurée au $\mathrm{IX}^{\mathrm{e}}$ siècle, cet office ne reçoit ici que des antiennes des laudes. On remarquera l'absence de l'office de saint Remi et en revanche, l'addition de la Vita Remedii du Pseudo-Fortunat (f $\left.107 \mathrm{v}^{\circ}-109 \mathrm{v}^{\circ}\right)$, c'est-à-dire la première vie et non celle d'Hincmar qui existait pourtant à cette époque ${ }^{58}$. Non conçu pour être noté, cet antiphonaire a toutefois reçu quelques additions neumatiques.

\section{Les bréviaires}

Très peu répandu dans le haut Moyen Âge, c'est surtout aux XIII ${ }^{\mathrm{e}}$ et XIV siècles que le bréviaire connaît une formidable expansion. Lorsqu'il comporte une notation musicale, le bréviaire revêt potentiellement l'intérêt d'un antiphonaire dont il rassemble en plus, outre le calendrier, les lectures de l'office (ou leçons) et les oraisons. Ses rubriques sont d'ailleurs très souvent détaillées. C'est pourquoi le bréviaire, qui au Moyen Âge fait office de livre plénier (un peu comme le missel plénier par rapport au graduel), représente un type de livre extrêmement important pour l'étude des offices dans le cadre de la liturgie ${ }^{59}$.

55. - D. DeFENTE (dir.), Saint-Médard..., op. cit. (n. 21), p. 43.

56. - A. De CARdevacque et A. Terninck, L'Abbaye de Saint-Vaast d'Arras, Arras, 1865, p. 66-73. 57. - Sur l'office de saint Denis, J.-F. Goudesenne, L'Office romano-franc de saint Denis (VIII $X^{e}$ siècle), Introduction et édition critique (Musicological Studies, Historiae, vol. LXV/6), The Institute of Mediaeval Music, Ottawa (en préparation).

58. - Nous ne citons ici parmi les offices du sanctoral que ceux qui sont directement originaires de la province de Reims.

59. - Sur les quelques centaines d'exemplaires qu'il répertorie, Leroquais n'en compte que 12 pour le $\mathrm{XI}^{\mathrm{e}}$ siècle et 39 pour le $\mathrm{XII}^{\mathrm{e}}$ siècle avec ou sans notation musicale; V. LEROQUAIS, Les bréviaires manuscrits des bibliothèques publiques de France, Paris, 1934, introduction, t. I, p. XXXV-XXXVI. 
Les bréviaires respectifs de Saint-Vaast et de Notre-Dame d'Arras sont les plus précieux de la province, tant le nombre d'offices propres du sanctoral qui y sont rassemblés est considérable ${ }^{60}$. Le premier, avec ses 554 folios sur deux colonnes $(191 \times 133 \mathrm{~mm})$, de la première moitié ou du milieu du XIII ${ }^{\mathrm{e}}$ siècle, avec notation carrée sur portée, rassemble plus de douze offices propres locaux, de la province de Reims et d'ailleurs (Liège, Normandie...), près de trente saints non grégoriens dans les litanies et plus d'une centaine, également non grégoriens, commémorés dans le sanctoral tout au long de l'année liturgique... (fig. 4). Cette abondance atteste la place centrale occupée par l'abbaye de Saint-Vaast dans la composition et la diffusion des offices en Gaule septentrionale.

Pour les saints de la province mentionnons saint Nicaise ( $\mathrm{f}^{\circ}$ 311-315), saint Vaast qui reçoit trois offices, la déposition ( $\mathrm{f}^{\circ} 343 \mathrm{v}^{\circ}-350$ ), l'octave $\left(\mathrm{f}^{\circ} 350 \mathrm{v}^{\circ}\right.$ $353 \mathrm{v}^{\circ}$ ) et la relation ( $\left.\mathrm{f}^{\circ} 401 \mathrm{v}^{\circ}-405\right)$, saint Hadulphe qui ne reçoit que quelques pièces pour sa déposition et sa translation ( $\left.f^{\circ} 432 \mathrm{v}^{\circ}-434 \mathrm{v}^{\circ}\right)$, saint Amand, qui ne reçoit qu'une antienne $\left(\mathrm{f}^{\circ} 433 \mathrm{v}^{\circ}\right)$, de même que les saints Crépin et Crépinien dont le nombre de pièces est très restreint $\left(\mathrm{f}^{\circ} 468 \mathrm{v}^{\circ}\right)$, de même saint Quentin ( $f^{\circ} 470$ ). Beaucoup d'autres offices recouvrent d'autres influences et d'autres secteurs géographiques : saint Gilles (Egidius) $\left(f^{\circ} 434 v^{\circ}-436 v^{\circ}\right)$, saint Léger d'Autun, martyrisé près d'Arras ( $f^{\circ} 458 \mathrm{v}^{\circ}$ $462 v^{\circ}$ ), saint Aycadre et saint Philibert, deux offices de provenance normande ${ }^{61}$, sans oublier l'invention de saint Étienne et la fête de la SainteTrinité, de provenance liégeoise et messine ${ }^{62}$. Cette abondance du sanctoral, apportant ainsi un certain déséquilibre, ne semble guère avoir gêné les moines de Saint-Vaast, du moins jusqu'à la Contre-Réforme.

Le second bréviaire, un peu plus tardif et moins prolixe que le précédent, de cursus canonial, nous transmet la liturgie de la cathédrale Notre-Dame d'Arras, très proche de celle de l'abbaye voisine ${ }^{63}$, avec ses 659 folios (257 x $171 \mathrm{~mm}$ ) écrits sur deux colonnes. Chaque office commence par une lettrine historiée : saint Vaast, dont les deux fêtes de la déposition et de la relation reçoivent ici les mêmes chants ( $\mathrm{f}^{\circ} 336-345$ et $510-510 \mathrm{v}^{\circ}$ ), les saints Crépin et Crépinien qui comportent ici un peu plus de pièces que dans les autres manuscrits $\left(f^{\circ} 537 v^{\circ}-540\right)$, de même que saint Quentin $\left(f^{\circ} 544-550 v^{\circ}\right)$.

60. - Arras, BM 465 et 412; V. LeroquaIs, Les bréviaires manuscrits..., op. cit. (n. 59), n 30 ; Dom L. Brou, « L'Ancien office de saint Vaast, évêque d'Arras », Études Grégoriennes, t. IV, Solesmes, 1961, p. 7-42; D. EscudIER, Le Scriptorium de Saint-Vaast d'Arras...

61. - A. LEGRIS, «L'École normande de chant liturgique », Revue Grégorienne, 7, 1922, p. 88-99 et p. 139-143; Dom R.-J. HeSBERT, Les manuscrits musicaux de Jumièges (Monumenta Musicae Sacrae), Mâcon, 1954.

62. - A. AudA, L'École musicale liégeoise au Xe siècle : Étienne de Liège, Bruxelles, 1923, p. 49 et 111-112.

63. - V. Leroquais, Les bréviaires manuscrits..., op. cit. (n. 59), n² 27; Dom L. Brou, « L'Ancien office... », art. cit., p. 37 et $s q q$. 


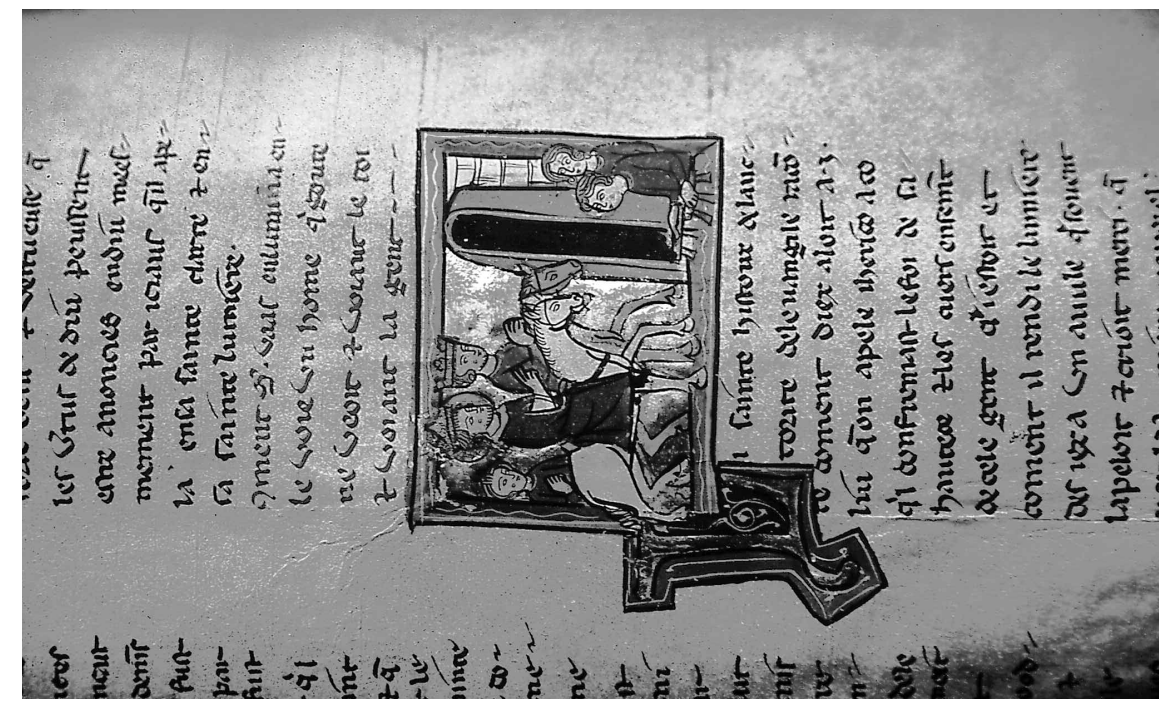

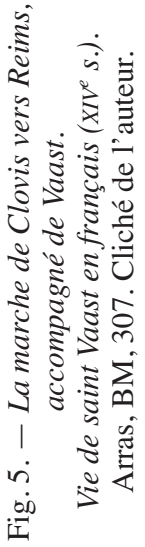

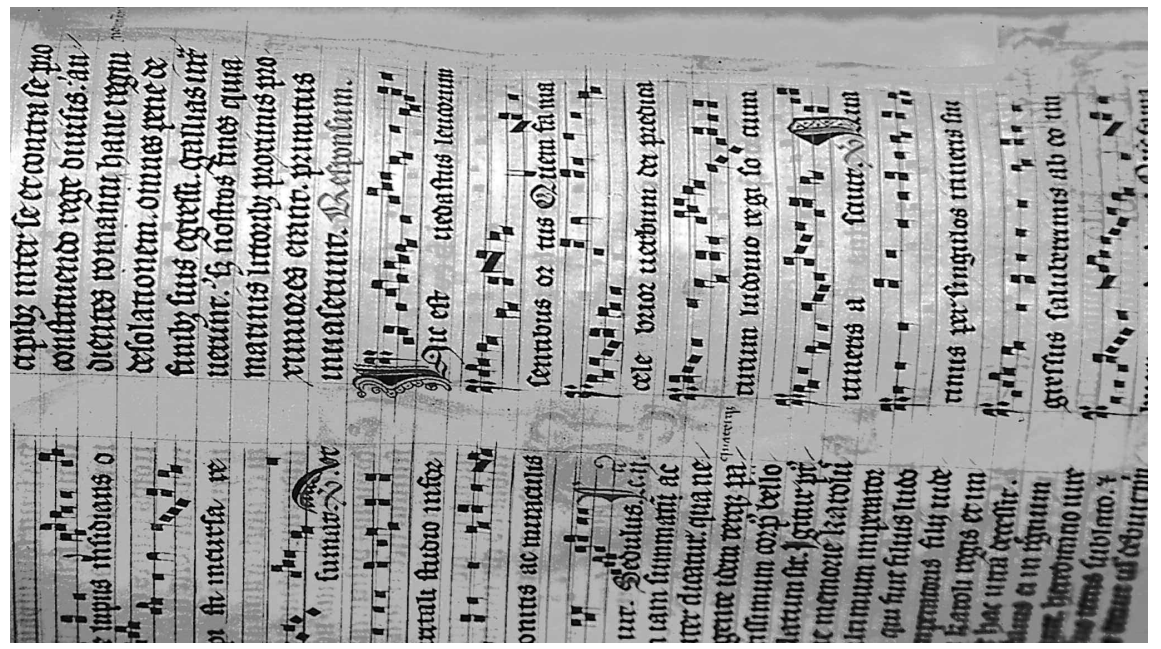

ช

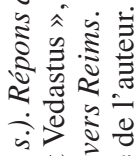

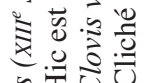

它记

ثँ

¿द्ध

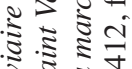

ป

के ะ

1.0

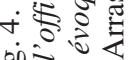

की 
On remarquera également, à la différence du bréviaire de l'Abbaye, la présence de l'office de saint Lambert, de provenance liégeoise (fo $\left.476 v^{\circ}-480 v^{\circ}\right)$.

\section{Quelques thèmes historiographiques}

\section{Les barbares et les Huns}

Les premières invasions barbares relatées dans le corpus des offices historiques de la province de Reims sont les incursions vandales de 407, relatées dans la Passion de saint Nicaise, dixième évêque de Reims, martyrisé avec sa sœur Eutropie et ses fidèles sur le parvis de Sainte-Marie de Reims ${ }^{64}$. Ces persécutions constituent la toile de fond de l'historia. Attesté dès la seconde moitié du $\mathrm{X}^{\mathrm{e}}$ siècle par l'antiphonaire de Noyon-Corbie, diffusé largement dans la province, l'office de saint Nicaise emprunte son texte à la Seconde Passion, qu'il combine aux psaumes tant dans les antiennes que dans les répons. Il fusionne les emprunts aux psaumes avec les épisodes historiques des textes hagiographiques. Le récit narratif progresse de façon chronologique et les psaumes cités se déroulent dans un ordre croissant. Il s'ouvre avec les invasions barbares, comme dans l'office et la Vita Remigii d'Hincmar (Ant. 3). Les laudes développent l'épisode de sa décollation, emprunté au chapitre six de la Seconde Passion: la fureur du glaive (Ant. 13), l'appel du saint avant sa décollation (Ant. 14), la céphalophorie (Ant. 15) puis l'ascension de son âme au ciel, "sur les ailes des vertus victorieuses ». Dans les répons, beaucoup d'événements renvoient à un épisode de la Bible : au cadre funeste des invasions barbares en Gaule fait pendant une citation de saint Matthieu invitant à ne pas craindre « ceux qui tuent le corps mais qui ne peuvent tuer l'âme ${ }^{65}$ (Rép. 1). La maîtrise des passions renvoie quant à elle à la fournaise dans Daniel (Rép. 2) ${ }^{66}$. Le répons suivant, évoquant la prédication, semble être une réécriture complète ou une invention (Rép. 3). Le thème des « armes spirituelles » paraphrase l'antienne Sicut tuba (Ant. 10) relatant un propos du saint (Rép. 4). Nicaise est présenté dans sa cathédrale aux côtés de sa sœur Eutropie, entourés de son assemblée de fidèles (Rép. 5). Le thème du bon pasteur et sa détermination à ne pas fuir les Vandales (Rép. 6 et 7) ne se présente plus vraiment comme une action en train de se faire mais plutôt comme une action relatée après coup. Les derniers répons sont consacrés à la décollation (Rép. 8).

Issu d'une production hagiographique assez différente de saint Remi, l'office de saint Vaast brosse également un portrait de Clovis complémentaire (fig. 5), d'après la Vita de Jonas de Bobbio, du VII ${ }^{\mathrm{e}}$ siècle ${ }^{67}$ et relate une autre

64. - M. Sot, Un historien et son église ..., op. cit. (n. 22), p. 372-376.

65. - Matthieu, 10, 28.

66. - Daniel, 3, 52 .

67. - L. Brou, « L'Ancien office de saint Vaast... », art. cit., p. 35; MGH, Scriptores Rerum Merovingicarum, III, chap. 6 et 7, p. 409-410. 
incursion barbare : Attila, roi des Huns, détruisit l'église et l'action évangélisatrice chez les atrébates, menée depuis le $\mathrm{II}^{\mathrm{e}}-\mathrm{III}^{\mathrm{e}}$ siècle ${ }^{68}$. La cité est symboliquement redevenue païenne, comme nous chante cette antienne du second nocturne de l'octave : « là où autrefois il y avait des chœurs de psalmistes, il (Vaast) y trouva un repaire de bêtes sauvages $\gg^{69}$.

\section{Clovis et la « gent » des Francs}

L'évocation des barbares revient de droit à un office plus répandu encore que le précédent et antérieur, tant dans sa composition que dans l'ancienneté des textes hagiographiques sous-jacents : l'office de saint Remi ${ }^{70}$, dans lequel le portrait de Clovis tient une place centrale, même si elle n'est pas exclusive. Il est particulièrement intéressant de constater qu'en plus du baptême de Clovis, c'est la férocité de la «gent barbare des Francs » qui est évoquée, souvent de façon métaphorique, par l'intermédiaire de saint Remi : il y a transposition des vertus du saint sur le roi, mais aussi du roi sur le saint ${ }^{71}$. Ainsi, Remi est présenté comme un chef de guerre (bellator invictus), un « triomphateur remarquable » (Ant. 10). Il calme la fureur du Seigneur, mais c'est bien en fait celle des Francs qu'il tempère (Rép. 4). Cette fureur renvoie au temps des invasions barbares, qui introduisent la Vita d'Hincmar : Post vindictam scelerum... L'ère de paix évoquée dans l'office n'est-elle pas la conséquence de la victoire sur les Alamans ? Saint Remi «n'est pas armé du bouclier ni de l'épée, mais des mérites de la sainteté » (Rép. 7). Comme JeanBaptiste, auquel il est volontiers comparé, il est un « chef glorieux, dont le rôle est de conduire son peuple, la gent barbare des Francs, à la foi catholique » (Ant. 19 et Rép. 8). La plupart de ces pièces qui brossent un portrait guerrier de Remi ou de Clovis sont des compositions littéraires et musicales originales, dont certaines auraient pu être intégrées comme telles à la Vita Remigii d'Hincmar' ${ }^{72}$.

Grâce à l'impulsion de l'archevêque Hincmar au milieu du IX siècle Remi est bien devenu un des grands patrons des royaumes francs, des Gaules, comme le chantent toutes ces hymnes composées pour lui dès le VIII ${ }^{\mathrm{e}}-\mathrm{IX}^{\mathrm{e}}$ siècle (Remigius presul meritis... Francorum Domino gentem peperit lucu-

68. - É. DE Moreau, Histoire de l'Église en Belgique..., op. cit. (n. 28), p. 54.

69. - J.-F. GOUDESENNE, Les offices historiques..., op. cit. (n. 4), t. II/2, p. 382.

70. - J.-F. GoudesenNE, « La musique de l'ancien office de saint Remi retrouvée (IXe siècle) », dans Michel Rouche (dir.), Actes du colloque Clovis, histoire \& mémoire, Reims, 19-25 septembre 1996, Paris, 1997, p. 111-113.

71. - Ibid.

72. - Il s'agit notamment de l'Ant. 10, Triumphator, entièrement écrite en vers rythmiques et reprise comme telle dans la Vie en prose d'Hincmar. Voir F. BAIX, « Les sources liturgiques de la Vita Remigii de Hincmar », Miscellenea Historica... Alberti de Meyer, I, Louvain, 1946, p. 211-227. J.-F. GOUDESENNE, « La musique de l'ancien office... », art. cit., p. 119-120. 
lentem...; Remigius presul inclite, patrone gentis Galice... ${ }^{73}$ ) et qui continueront d'être chantées tout au long des siècles, dans de nombreuses régions qui, selon les avatars de l'histoire, ne faisaient pas ou plus partie du Royaume de France (Aix-la-Chapelle, Cologne, Liège, Italie...). Sinon, c'est l'office de saint Vaast, tout différent dans son milieu d'origine, son époque et ses dépendances hagiographiques qui brosse un portrait du chef franc Clovis, avant son baptême à Reims.

\section{Les pouvoirs des saints}

\section{Baptême de Clovis (fig. 6)}

S'il nous paraît évident que l'office de saint Remi est l'œuvre la plus à même d'évoquer cet épisode central et emblématique de l'histoire des Francs, soulignons que Clovis n'y tient pas une place exclusive et aussi importante qu'on pourrait le croire. En effet, la première Vita, dite Vita Remedii, attribuée à un Pseudo-Fortunat, $\mathrm{du} \mathrm{VI}^{\mathrm{e}}$ siècle, passe sous silence cet événement. Comme l'explique M. Heinzelmann, les hagiographes mérovingiens ne semblent guère avoir manifesté d'intérêt pour le baptême de Clovis et c'est plutôt l'époque carolingienne, notamment avec Alcuin puis à sa suite Hincmar, que la réécriture des Vitae mérovingiennes manifeste une préoccupation plus essentielle à ce sujet ${ }^{74}$. Il semblerait donc que c'est sous Tilpin et même peut être sous Hincmar que l'évocation du baptême aurait été interpolée, à partir d'autres textes et peut-être même à partir d'un office antérieur, pour constituer un tout plus homogène ${ }^{75}$. C'est dans le second nocturne des matines que le baptême est évoqué, particulièrement avec l'antienne Gentem francorum reprise intégralement dans la Vita Remigii d'Hincmar. Elle rapporte un moment clé de ce baptême, avec le thème de la sainte ampoule : une colombe apporte du ciel « le divin chrême $»^{76}$. Dans l'office de saint Vaast, plusieurs pièces semblent faire écho à la célèbre apostrophe de saint Remi, rapportée par Grégoire de Tours, Sicambre, depone colla... Lorsque le compositeur de l'office chante ce vers : per quem Christo fera gentium corda perdomuit superba principum colla subegit... ${ }^{77}$ Mais elles semblent bien être d'une époque plus tardive, peut-être du milieu du IX ${ }^{\mathrm{e}}$ siècle.

\footnotetext{
73. - Voir l'édition des textes infra.

74. - M. HeinzelmanN, "Clovis dans le discours hagiographique du $\mathrm{VI}^{\mathrm{e}}$ au $\mathrm{IX}^{\mathrm{e}}$ siècle ", Bibliothèque de l'École des Chartes, 154:1, 1996, p. 101 et sqq.

75. - J.-F. GoudeSENNE, « La musique de l'ancien office de saint Remi... », art. cit., p. 119-120.

76. - Voir infra, Ant. Gentem francorum.

77. - Ant. 22, Presulis summi.
} 

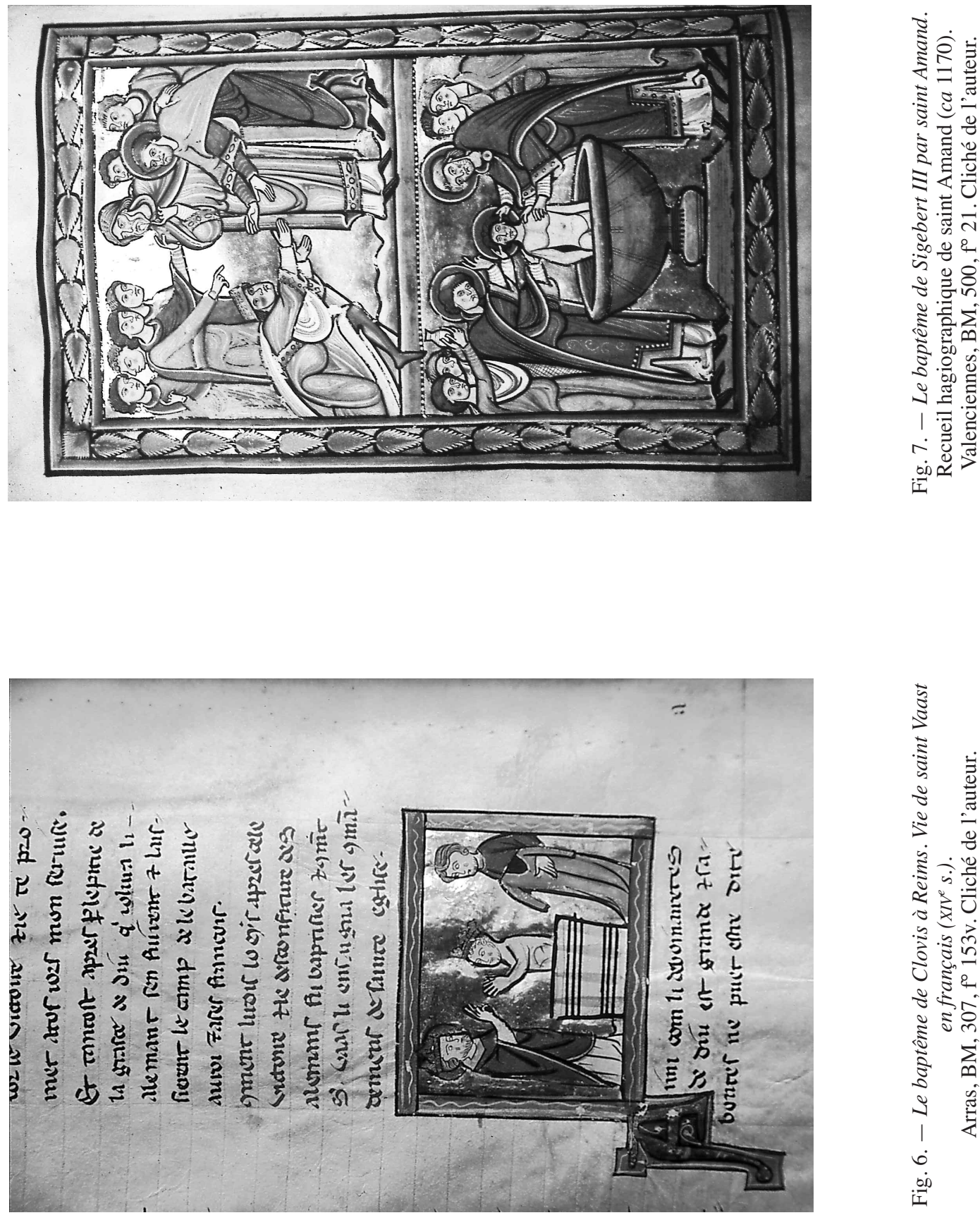


\section{Baptême de Sigebert III, fils de Dagobert (fig. 7)}

L'office de saint Amand relate un autre baptême, certes beaucoup moins prestigieux et symbolique que le précédent, mais qui illustre néanmoins les pouvoirs thaumaturgiques du saint tant l'égard des humbles que des membres des familles princières ou royales. Les laudes sont consacrées à l'action évangélisatrice d'Amand dans le Nord de la Gaule et au baptême de Sigebert III, fils du roi Dagobert, qui rehausse de prestige le monastère d'Elnone, jadis fondé sous la protection de ce dernier ${ }^{78}$. La première antienne (Ant. 16) ouvre la série en insistant sur le paganisme encore très répandu dans les contrées septentrionales, se poursuit par la prosternation du roi Dagobert implorant le pardon du saint (Ant. 17) puis par le baptême de son fils malade et condamné, qui répond au sacrement par un amen miraculeux le ramenant à la vie et le sauvant de la mort pourtant prédite (Ant. 18-20). Ce passage important de l'hagiographie amandinoise sera repris dans le second office versifié, composé probablement au $\mathrm{X}^{\mathrm{e}}$ ou XI $\mathrm{XI}^{\mathrm{e}}$ siècle $^{79}$.

\section{Guérisons et miracles auprès des filles d'Alaric et de Thierry III, à la cour de Clotaire}

Les guérisons miraculeuses sont abondamment illustrées dans les historiae. Mais seules quelques-unes se rapportent aux dynasties royales. Dans l'office de saint Remi, Clovis bien qu'ayant une place centrale, ne détient pas le monopole et son terrible ennemi, le roi wisigoth Alaric, est également secouru par l'évêque de Reims pour sa fille moribonde ${ }^{80}$. Ce récit de la résurrection de la fille du roi occupe quasiment toutes les laudes (Ant. 12-16) ainsi qu'un répons (Rép. 9). Ce récit est lui-même issu de la Vita prima où il occupe une place essentielle. On trouve un récit analogue dans un office dédié au disciple de Remi, saint Thierry, composé probablement vers 900 par Hucbald de Saint-Amand. Les laudes (Ant. 16-21) sont consacrées à la résurrection de la fille du roi Thierry III; le parallèle avec la fille d'Alaric dans l'office de saint Remi, également dans les laudes, trahit sans aucun doute une influence liturgique dans cette composition, car le choix du chapitre XI de la seconde Vita pour les six antiennes ne peut être que délibéré. Thierry III d'Austrasie sera reconnaissant à l'égard de son saint patron : lors de la mort du saint (Rép. 11) on relate sa participation personnelle aux obsèques. Un répons complémentaire ajouté (Rép. 13) le présente en train de porter le saint sur ses épaules pour le conduire en sa dernière demeure. Des remaniements probablement postérieurs à la réforme d'Adalbéron de Reims renforcent les liens entre le monastère de Saint-Thierry et les maires austrasiens ${ }^{81}$.

\footnotetext{
78. - É. De Moreau, Histoire de l'Église en Belgique..., op. cit. (n. 28), chap. 3 , § 7 (Amand et Dagobert I $\mathrm{I}^{\mathrm{er}}$.

79. - J.-F. GOUDESENNE, Les offices historiques..., op. cit. (n. 4), p. 476.

80. - V. MARTin-HeInZELMANN, « Clovis dans le discours hagiographique... », art. cit., p. 99.

81. - J.-F. GoUdESENNE, Les offices historiques...., op. cit. (n. 4), p. 458.
} 
Un répons de l'office de saint Vaast, issu de la Vita d'Alcuin (chap. 3, § 6), elle-même réécriture de la Vita antérieure de Jonas de Bobbio, relate un miracle effectué à la cour du roi Clotaire Ir (chap. 7). Un certain Hocinus convie l'évêque d'Arras ${ }^{82}$. Ce dernier remarque à l'entrée du palais des vases remplis de cervoise dont les uns étaient destinés aux chrétiens et les autres, consacrés par des rites spéciaux, réservés aux païens. Par un signe de croix sur ces amphores, Vaast les réduit en pièces; il chasse des démons, dénonce les artifices de l'idolâtrerie. Cet appel à la conversion (plusieurs convives demandent le baptême à l'issue de ce miracle) renvoie au $5^{\mathrm{e}}$ répons, Qui de rupe, cité plus haut à propos du baptême.

D'autres offices au rayonnement beaucoup plus limité, font également mention de personnages historiques, certes mineurs comme par exemple Adroald et le comte Walbert dans les offices de saint Bertin et de saint $\mathrm{Omer}^{83}$. Ou encore, le maire du palais Ebroïn et sa cour dans l'office de saint Léger. Le roi Dagobert apparaît de nouveau très épisodiquement dans les offices de saint Omer et de saint Aubert, postérieurs à l'an mil, dans des chants où l'on évoque le droit de regard du roi sur la nomination des évêques. En revanche, il paraît étonnant que plusieurs saints très importants, dont les offices ont été diffusés au niveau provincial et même " national » ne reçoivent aucune dimension historiographique dans leurs offices : il s'agit de saint Éloi et de saint Médard. Très haut dignitaire du royaume sous Dagobert puis Clovis II, Éloi a reçu un office avant le milieu du $\mathrm{X}^{\mathrm{e}}$ siècle ${ }^{84}$, qui ne fait quasiment aucune mention d'ordre historiographique; les passages de la Vita Eligii du Pseudo-Ouen qui ont été retenus pour l'office ont été délibérément choisis autour des thèmes moraux et apologétiques et semblent avoir évincé tout récit trop circonstancié. De même, l'évêque de Noyon Médard, patron de la dynastie mérovingienne puis carolingienne, dont l'office reçoit une place d'honneur dans l'antiphonaire de Charles le Chauve daté des environs de 870 (Compendiensis), ne développe pas tellement de thèmes ayant trait à l'historiographie de la royauté franque ${ }^{85}$. Pourrait-on en déduire que les rois et les puissants ecclésiastiques du royaume, instigateurs des cultes et de leur développement dans la liturgie des églises des Gaules, ne cherchaient pas systématiquement une représentation directe de la monarchie franque dans la célébration du culte divin?

82. - É. DE Moreau, Histoire de l'Église en Belgique ...., op. cit. (n. 28), p. 54-55.

83. - Une miniature du $\mathrm{XI}^{\mathrm{e}}$ siècle assez célèbre représente le baptême d'Adroald par saint Omer (Saint-Omer 698, fo 15). C. Deremble, « L'enluminure », Nord roman : Flandre, Artois, Picardie, Laonnois, Zodiaque (La nuit des temps), 1994, p. 293 et pl. 128-129.

84. - D'après la date de l'antiphonaire de Noyon (Paléographie musicale, t. XVI, Solesmes, 1955).

85. - Édité par R. Jonsson pour le texte littéraire, Historia..., op. cit. (n. 12), p. 206 et J.-F. GoudesenNe pour le texte musical, Les offices historiques..., op. cit. (n. 4), t. II/2, p. 434 et sqq. 


\section{Conclusion}

La poursuite de la réforme liturgique aux $\mathrm{VIII}^{\mathrm{e}}$ et $\mathrm{IX}^{\mathrm{e}}$ siècles promue tant par le pouvoir royal et impérial que par les communautés ecclésiastiques et les intellectuels, laïcs ou religieux, a favorisé l'émergence d'une création littéraire et musicale extrêmement florissante, renforcée dès l'arrivée en Gaule septentrionale du grand magister et conseiller de Charlemagne, Alcuin, à la fin du VIII ${ }^{\mathrm{e}}$ siècle. Radicalement opposés à une orientation monobiblique de la liturgie souhaitée par Agobard de Lyon ${ }^{86}$, les écoles de Reims et du Nord de la Gaule proposent à la chrétienté latine dans son universalité, bien avant l'élection au siège papal de l'archevêque de Reims, Gerbert d'Aurillac, des antiphonaires dans lesquels les récits historiques relatant des faits et gestes d'une époque plutôt récente, s'inscrivent en contrepoint aux textes scripturaires et séculaires de la Bible.

En effet, la célébration de l'Office divin ne semblait pouvoir exclure la commémoration solennelle dans la liturgie, des grands faits d'une sorte d'Historia Francorum, psalmodiée, chantée, déclamée à travers les gesta des saints martyrs ou confesseurs, athlètes de Dieu, héros dignes de figurer dans le cycle de l'année liturgique aux côtés de la Vierge Marie, des apôtres et des patriarches de l'Ancien Testament. Ils entraînent avec eux la mémoire de nombreux personnages historiques et véhiculent des représentations, qu'on retrouve dans l'iconographie et qui prennent une place importante dans l'histoire des mentalités médiévales. N'est-ce pas là d'ailleurs, dans cette audace de pérenniser par la liturgie tout un pan non biblique et récent de l'histoire humaine, que l'on pourrait être tenté d'entrevoir un des aspects essentiels de l'unification dite « romano-franque » de la liturgie et de la musique?

Mots-clés : manuscrits, hagiographie, musique (liturgique), liturgie, historiographie, histoire des textes, culte des saints, période carolingienne, Gaule du Nord.

86. - Lors de la Contre-Réforme c'est cette même question doctrinale relative à la place du culte des saints dans la liturgie qui sera de nouveau remise en question; beaucoup d'offices locaux seront alors supprimés et remplacés par des textes bibliques. 


\section{Sigles utilisés}

Ant. antienne

Rép. répons

AASS Acta Sanctorum quotquot urbe coluntur, Bruxelles, Société des Bollandistes, 1643-1894, 70 vol.

BHL Bibliotheca Hagiographica Latina antiquae et mediae aetatis, 2 vol., Société des Bollandistes (Subsidia Hagiographica, 6), Bruxelles, 18981901 ; supplément, 1911; supplément, éd. Henri Fros (Subsidia Hagiographica, 70), 1986.

CAO Corpus antiphonalium officii rerum ecclesiasticarum documenta, éd. R.-J. Hesbert (Series maior, Fontes, 7-12), Rome, 1963-1979, 6 vol.

MGH Monumenta Germaniae Historica.

\section{Vitae sanctorum citées}

Vita Amandi, BHL 332.

Fulbert de Chartres (?), Vita Autberti, BHL 861.

Guntbert (?), Vita metrica sancti Bertini, BHL 1292.

Pseudo-Ouen, Vita Eligii, BHL 2474.

Fortunat, Carmen et Vita sancti Medardi, BHL 5863 et 5864 (opus geminum).

Seconde Passion anonyme de saint Nicaise, BHL 6076.

Secunda Vita des saints Omer, Bertin et Winoc, BHL 1290; Miracula, BHL 1291.

Pseudo-Fortunat, Vita Remedii ( $\mathrm{vI}^{\mathrm{e}}$ siècle) BHL 7150.

Hincmar de Reims, Vita Remigii (ca 870), BHL 7152.

Prima et Secunda Vita Theoderici, BHL 8059 et 8060.

Jonas de Bobbio, Vita Vedasti (ca 642), BHL 8501.

Alcuin, Vita Vedasti (ca 800), BHL 8506.

\section{Édition de textes musicaux}

Les musicologues ont pour usage de proposer aujourd'hui des éditions diplomatiques des textes notés. La notation carrée, notée sur portée de quatre lignes avec clef est directement transcrite d'après les livres liturgiques des $\mathrm{XII}^{\mathrm{e}}, \mathrm{XIII}^{\mathrm{e}}$ et $\mathrm{XIV}^{\mathrm{e}}$ siècles. Au-dessus, on superpose des notations dites neumatiques, très souvent antérieures (du IX ${ }^{\mathrm{e}}$ au XII ${ }^{\mathrm{e}}$ siècle), dont l'intérêt est rythmique plutôt que mélodique.

\section{Sources :}

Saint Amand

Recueil hagiographique de Saint-Thierry de Reims, Vatican, Reg. Lat. 466, fin X⿳⺈ siècle, f ${ }^{\circ} 101$. Antiphonaire de Saint-Amand, Valenciennes BM, 114, de la fin du XII ${ }^{\mathrm{e}}$ siècle, $\mathrm{f}^{\circ} 120 \mathrm{v}$.

Saint Vaast

Liber Miraculorum d'Albert, Arras, BM, 734, ca 1030 ?, f 82.

Bréviaire de Saint-Vaast d'Arras, Arras, BM, 465, XIII' siècle, f ${ }^{\circ}$ 344v.

Saint Remi

Recueil de Notre-Dame de Reims, BNF lat. 5595, fin X $X^{\mathrm{e}}$ siècle, $\mathrm{f}^{\circ} 82$.

Bréviaire de Châlons, BNF lat. 1259, XIII' siècle, fo 356v.

Recueil hagiographique de Reims, Vercelli Biblioteca capitolare 205, fin $\mathrm{X}^{\mathrm{e}}$ siècle, $\mathrm{f}^{\circ} 137$. 
Office de saint Amand.

A. Amandus sanctissimus (I)

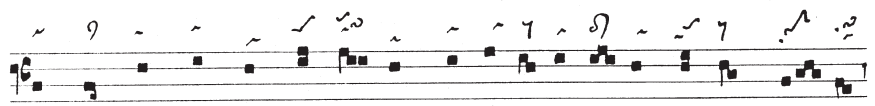

A -mant-dus sanc-tis -si-mus at-que re -li-gi-o-sis-si-mus pu - er

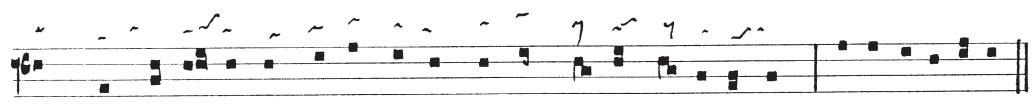

ex chris-ti-a-nis atque incly-tis pa-ren-ti-bus e-di-tus est. e u o u a e

Office de saint Vaast.

A. In conspectu regis $(23-\mathrm{II})$

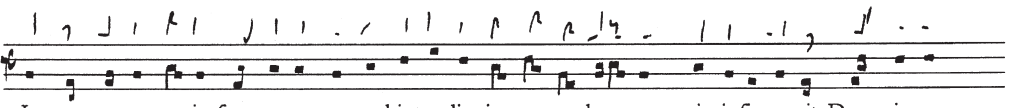

In conspectu re -gis franco-rum et multi-tu -di -nis po-pu - lo - rum, mi -ri -fi -ca -vit Do-mi-nus

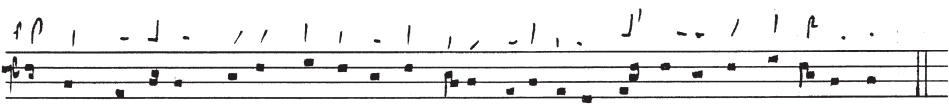

sanctum Ve-dastum, cu-ius pre-ci-bus annu -ens resti -tu -it ce-co lu-men o-cu-lo-rum.

Office de saint Remi.

R. Post vindictam (2-II)

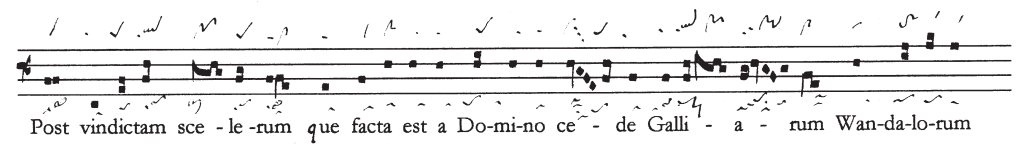

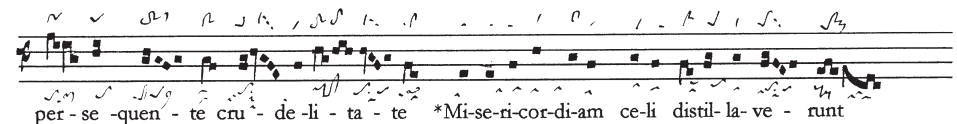
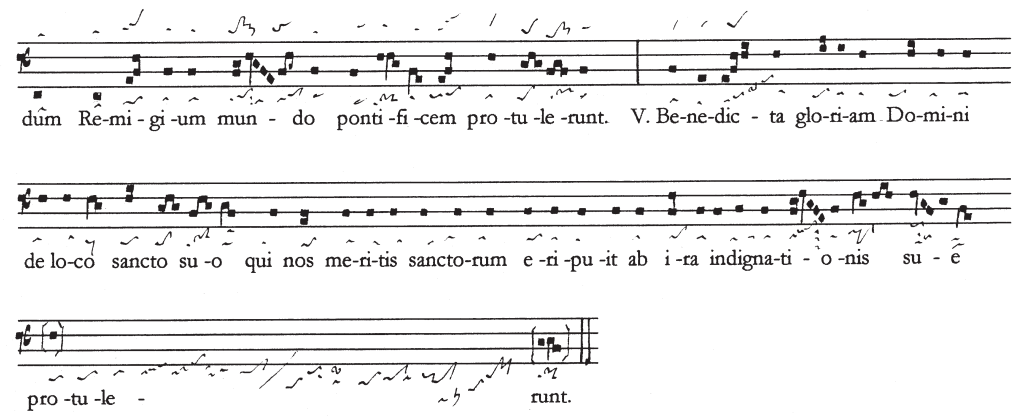


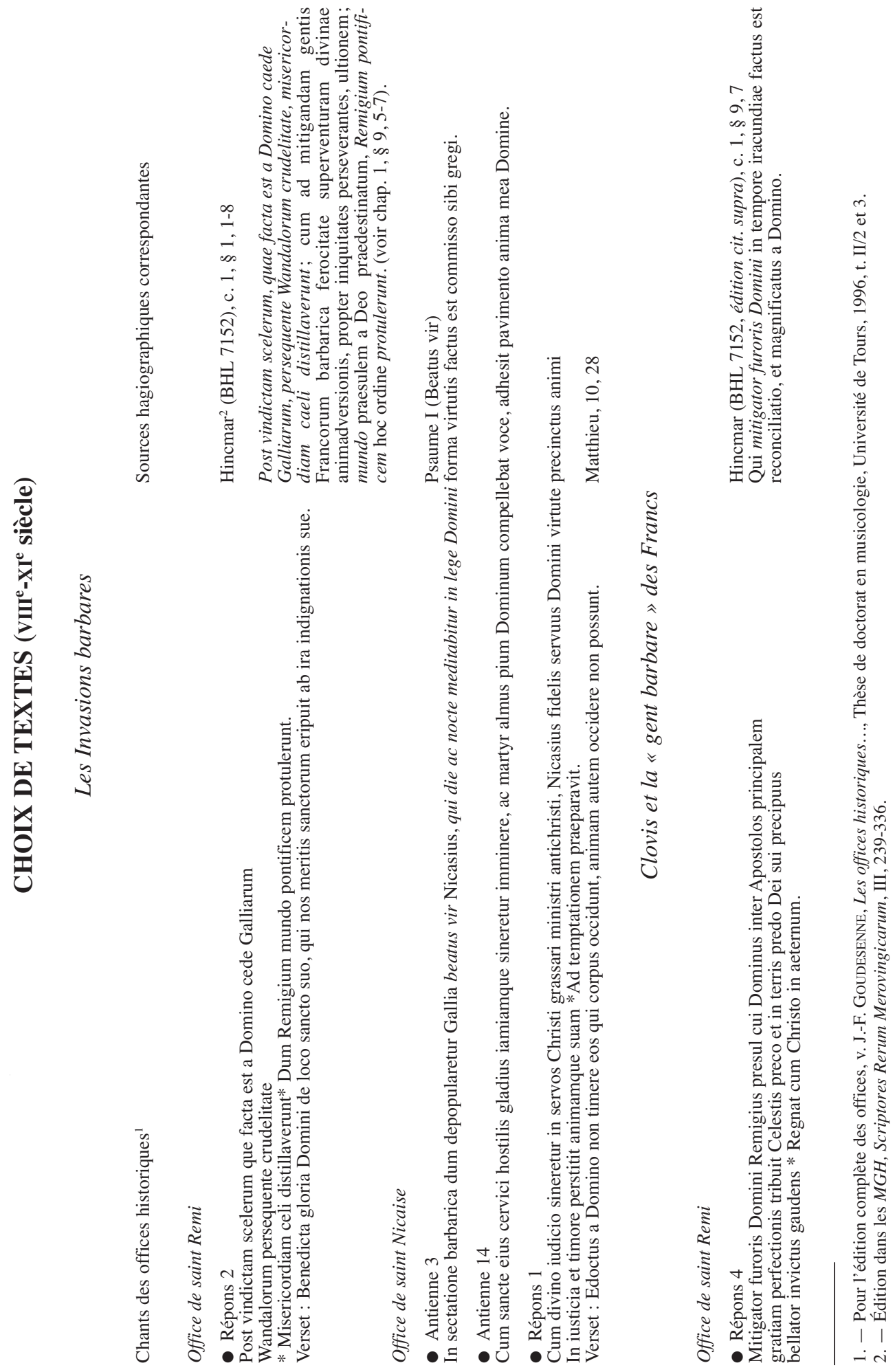




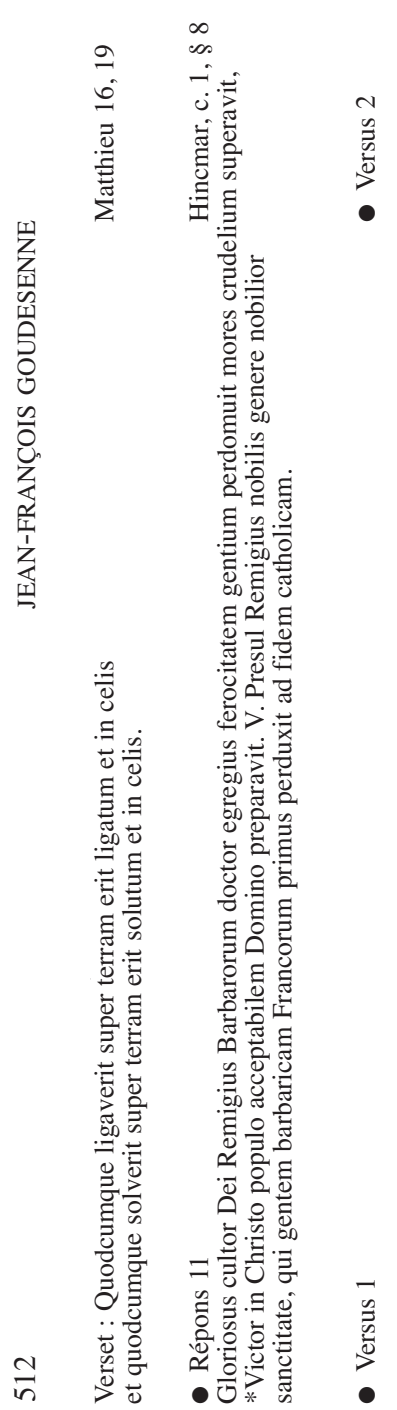

I

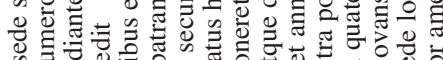

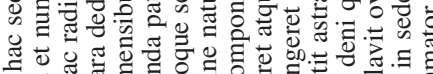

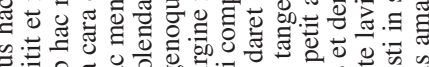

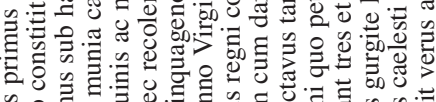

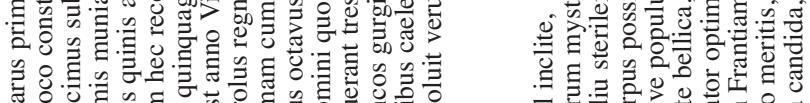

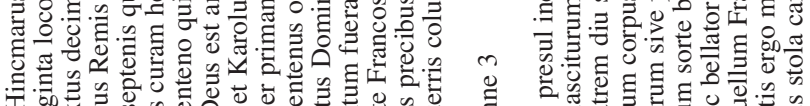

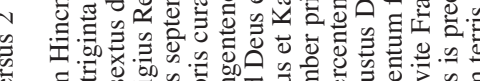

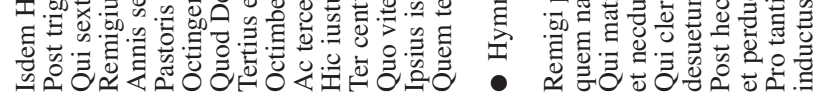

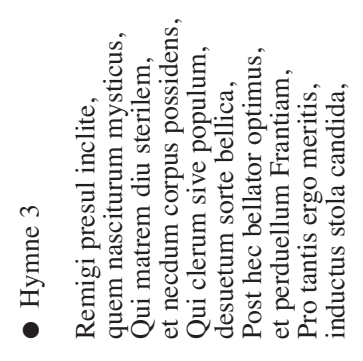

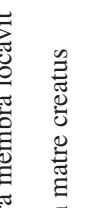

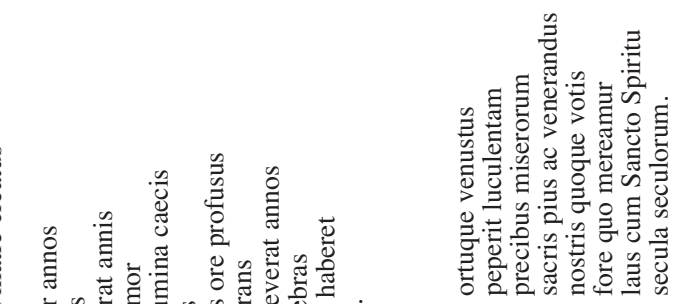
营.

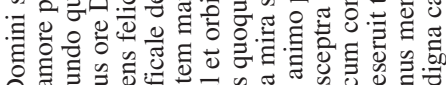

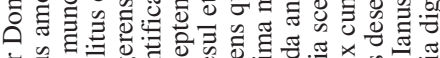

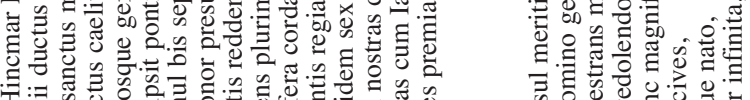

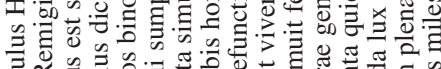

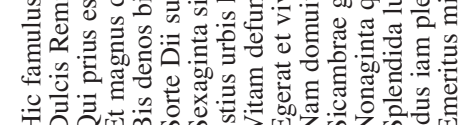

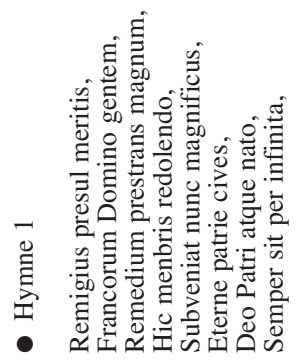



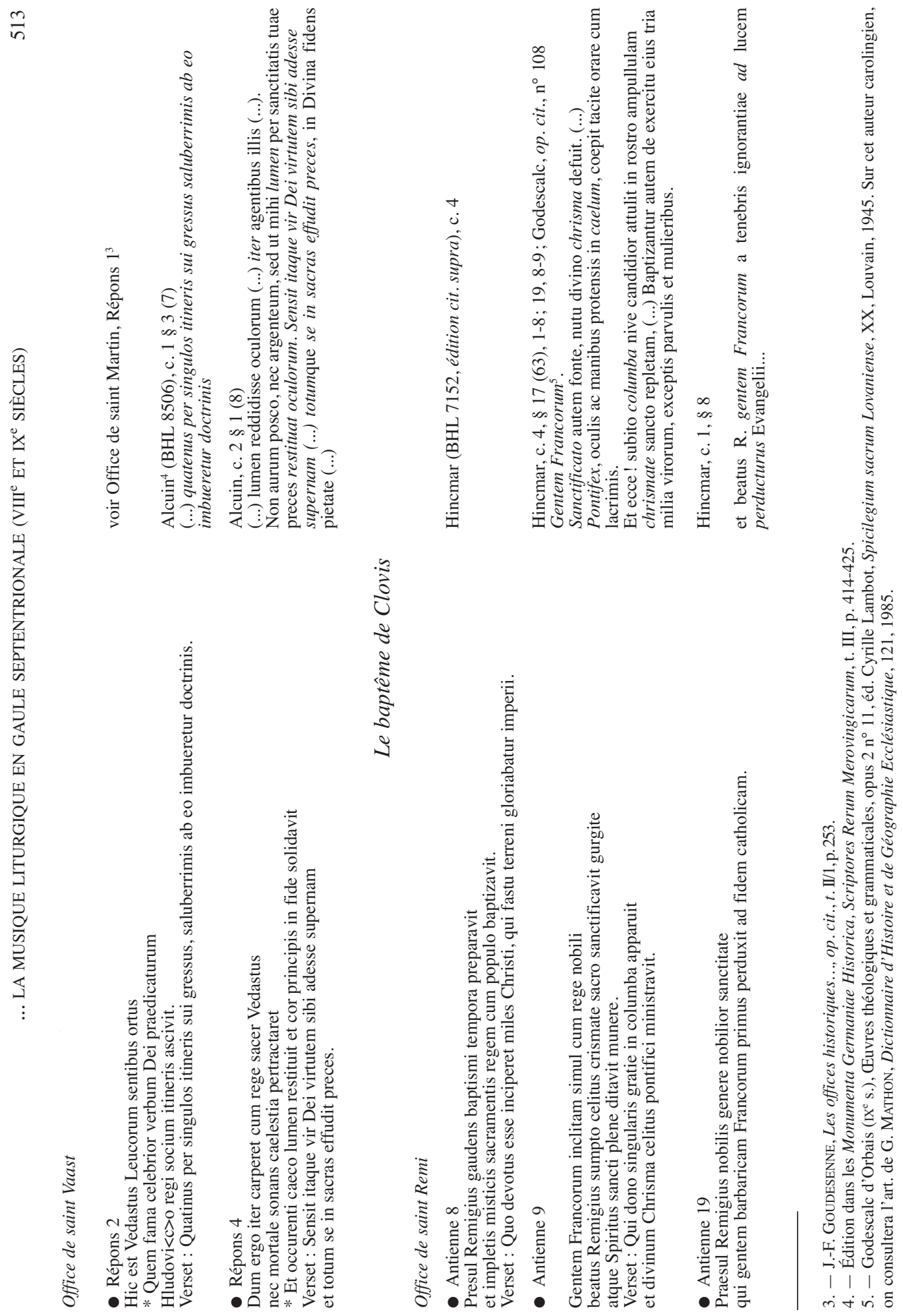


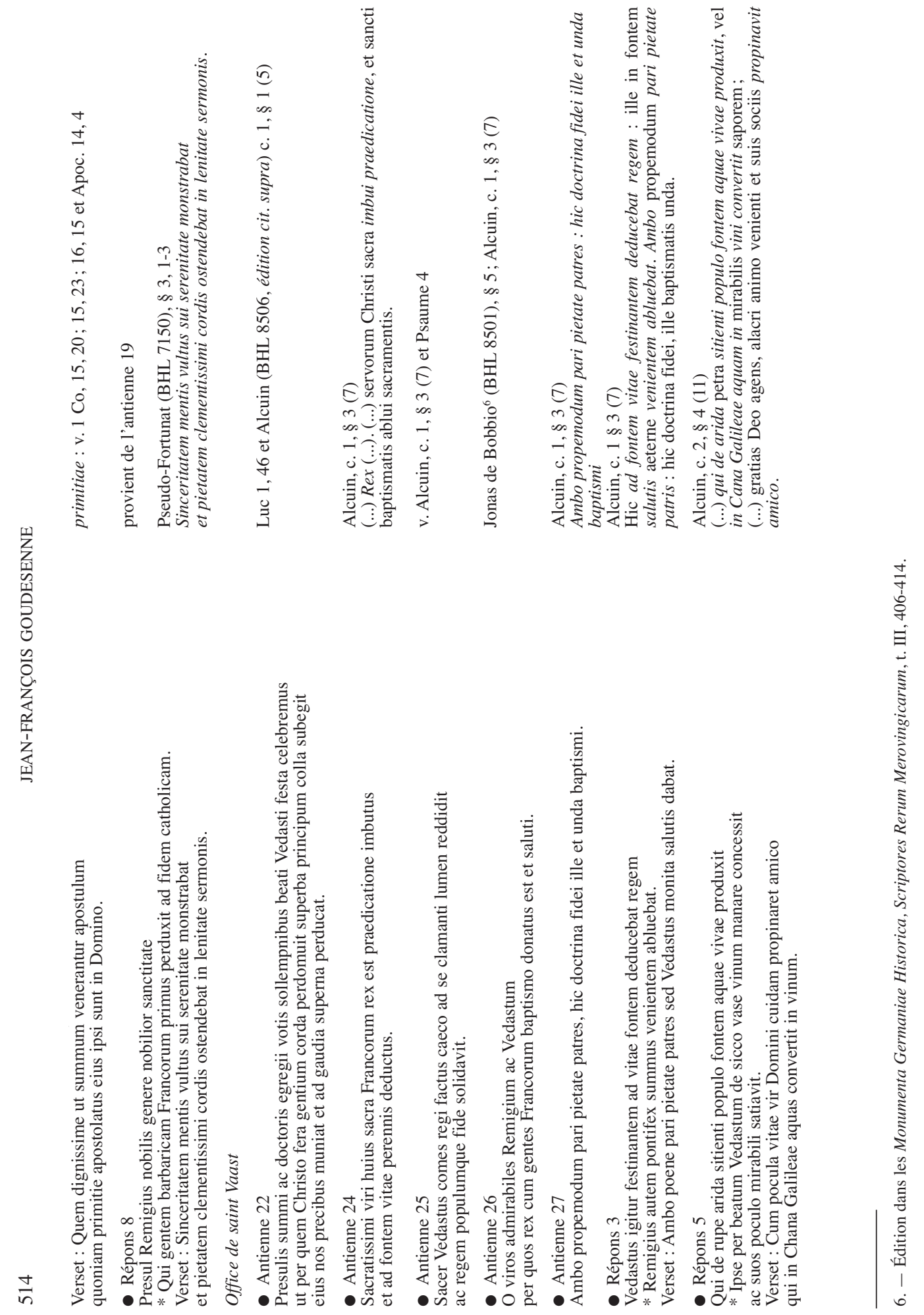



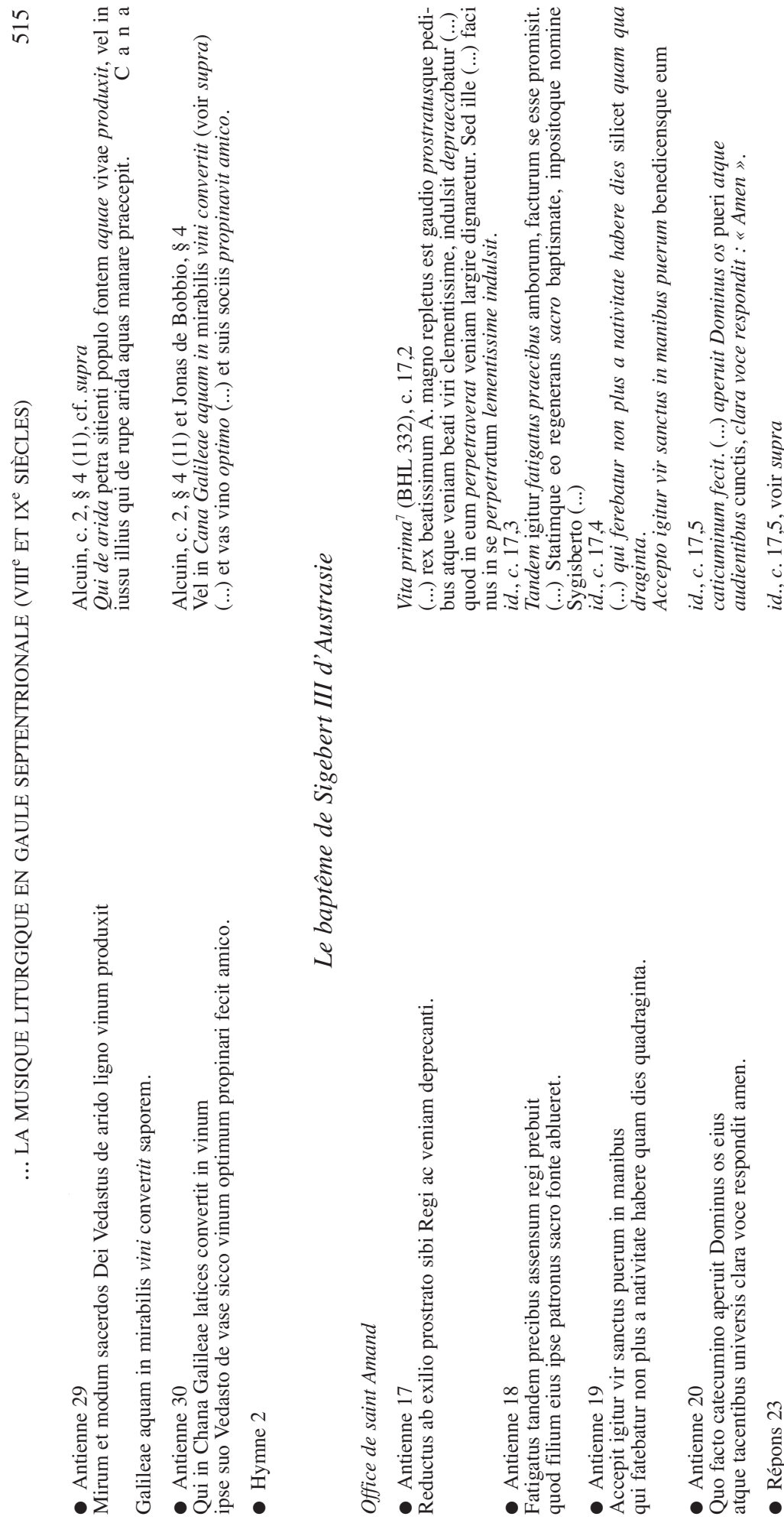


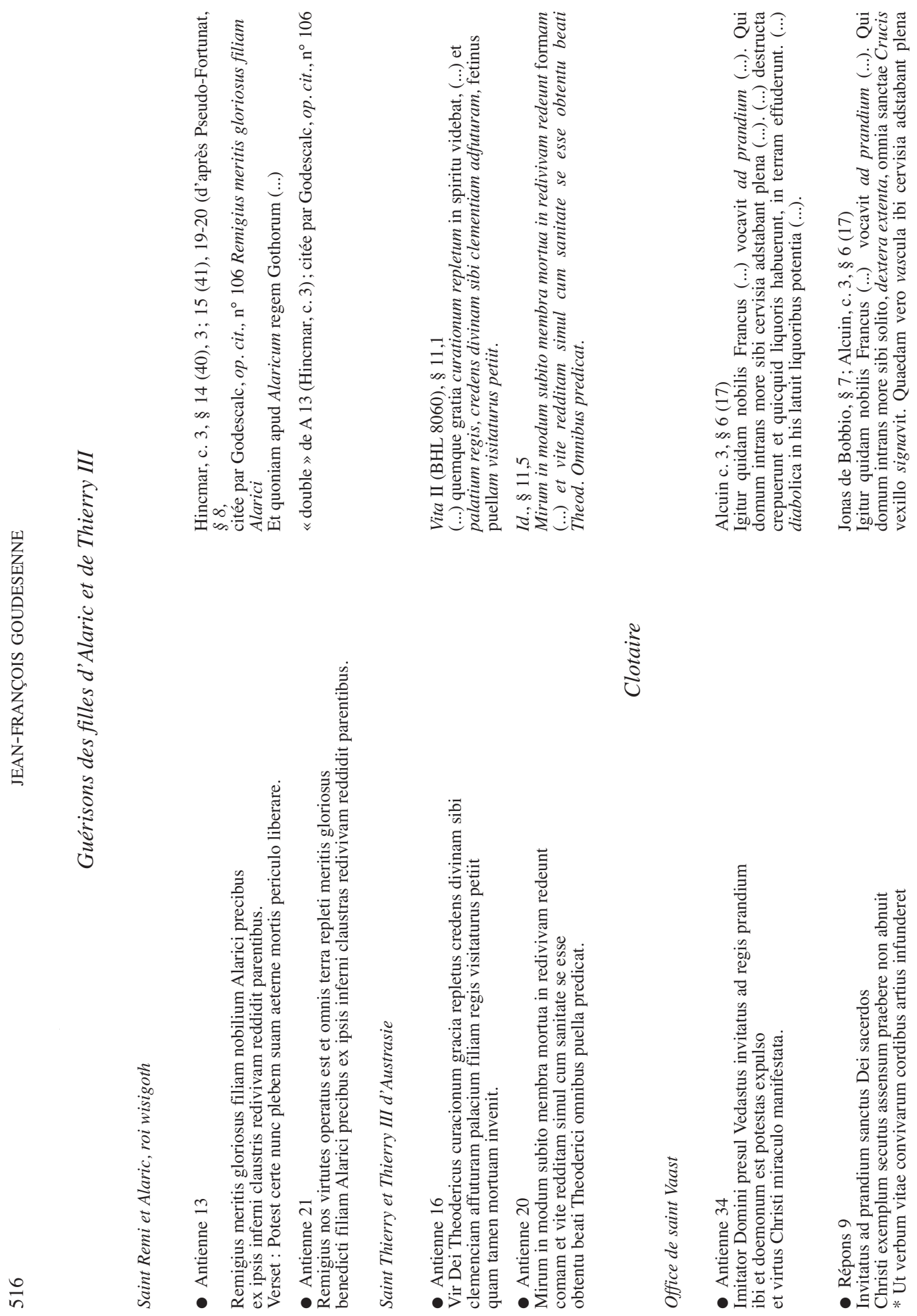




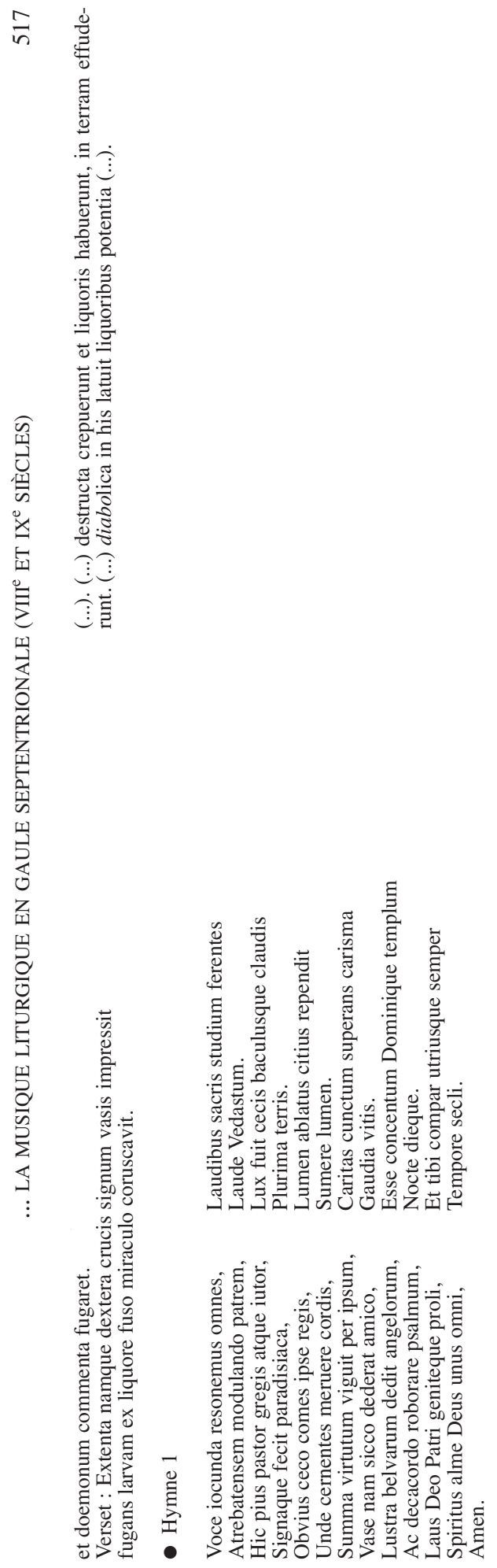

